\title{
A chemical probe technique for the determination of reactive halogen species in aqueous solution: Part 1 - bromide solutions
}

\author{
B. M. Matthew ${ }^{1, *}$ and C. Anastasio ${ }^{1}$ \\ ${ }^{1}$ Atmospheric Science Program, Department of Land, Air \& Water Resources, University of California, Davis, USA \\ *now at: Hach Company, Loveland, Colorado, USA
}

Received: 16 November 2005 - Published in Atmos. Chem. Phys. Discuss.: 2 February 2006

Revised: 27 April 2006 - Accepted: 8 May 2006 - Published: 29 June 2006

\begin{abstract}
Reactive halogen species $\left(\mathrm{X}^{*}=\mathrm{X}^{\bullet}, \mathrm{X}_{2}^{-}, \mathrm{X}_{2}\right.$ and $\mathrm{HOX}$, where $\mathrm{X}=\mathrm{Br}, \mathrm{Cl}$, or I) in seawater, sea-salt particles, and snowpacks play important roles in the chemistry of the marine boundary layer. Despite this, relatively little is known about the steady-state concentrations or kinetics of reactive halogens in these environmental samples. In part this is because there are few instruments or techniques that can be used to characterize aqueous reactive halogens. To better understand this chemistry, we have developed a chemical probe technique that can detect and quantify aqueous reactive bromine and chlorine species $\left(\mathrm{Br}^{*}(\mathrm{aq})\right.$ and $\left.\mathrm{Cl}^{*}(\mathrm{aq})\right)$. This technique is based on the reactions of short-lived $\mathrm{X}^{*}(\mathrm{aq})$ species with allyl alcohol $\left(\mathrm{CH}_{2}=\mathrm{CHCH}_{2} \mathrm{OH}\right)$ to form stable 3-halo-1,2-propanediols that are analyzed by gas chromatography. Using this technique in conjunction with competition kinetics allows determination of the steady state concentrations of the aqueous reactive halogens and, in some cases, the rates of formation and lifetimes of $X^{*}$ in aqueous solutions. We report here the results of the method development for aqueous solutions containing only bromide $\left(\mathrm{Br}^{-}\right)$.
\end{abstract}

\section{Introduction}

Gaseous and aqueous reactive halogen species $\left(\mathrm{X}^{*}\right.$, where $\mathrm{X}=\mathrm{Br}, \mathrm{Cl}$, or I) play important roles in the chemistry of marine regions. In solution, such as deliquesced sea-salt particles and surface seawater, aqueous reactive halogen species $\left(\mathrm{X}^{*}(\mathrm{aq})=\mathrm{X}^{\bullet}, \mathrm{X}_{2}^{-}, \mathrm{X}_{2}\right.$ and $\left.\mathrm{HOX}\right)$ are important for a number of reasons. For example, model studies of the remote marine boundary layer (MBL) have predicted that hypohalous acids $(\mathrm{HOBr}$ and $\mathrm{HOCl}$ ) are significant oxidants for $\mathrm{S}(\mathrm{IV})$ in sea-salt particles and MBL clouds (Vogt et al., 1996; Keene and Savoie, 1999; von Glasow et al., 2002b). It has also

Correspondence to: C. Anastasio

(canastasio@ucdavis.edu) been suggested that the photo-oxidation of halides can lead to the abiotic formation of halogenated organic compounds in seawater (Gratzel and Halmann, 1990; Moore and Zafiriou, 1994) and in polar snowpacks (Swanson et al., 2002).

In addition, halide reactions in sea-salt particles are closely linked to gas-phase chemistry through heterogeneous processes. For example, sea-salt particles and surface snowpack are important sources of gaseous reactive halogen species such as $\mathrm{Br}_{2}$ and $\mathrm{BrCl}$ to the MBL (McConnell et al., 1992; Sander and Crutzen, 1996; Vogt et al., 1996; Michalowski et al., 2000; Foster et al., 2001; von Glasow et al., 2002a). A growing body of evidence indicates that these reactive gaseous halogens significantly influence the global budgets of tropospheric species such as ozone, hydrocarbons and mercury. For example, in Arctic regions springtime ozone depletion and hydrocarbon loss have been linked to $\mathrm{Br}^{\bullet}$ and $\mathrm{Cl}^{\circ}$, respectively (Barrie et al., 1988; Jobson et al., 1994; Bottenheim et al., 2002). The recently described earlymorning destruction of ozone in both the mid-latitude and sub-tropical marine boundary layers has also been attributed to halogen chemistry (Nagao et al., 1999; Galbally et al., 2000; von Glasow et al., 2002a). Satellite and ground-based measurements of $\mathrm{BrO}^{\bullet}$ (produced from the reaction of $\mathrm{Br}^{\bullet}$ with $\mathrm{O}_{3}$ ) have revealed that the bromine-catalyzed destruction of ozone is widespread in the troposphere, occurring in the Arctic and Antarctic (Richter et al., 1998), as well as near saline lakes such as the Dead Sea (Hebestreit et al., 1999) and Great Salt Lake (Stutz et al., 2002). In addition to these effects, a recent model of halogen chemistry in the mid-latitude $\operatorname{MBL}\left(30^{\circ} \mathrm{N}\right)$ has indicated that dimethyl sulfide (DMS) oxidation increases by $\sim 60 \%$ when reactions with $\mathrm{BrO}^{\bullet}$ are considered (von Glasow et al., 2002b). The deposition of mercury in Arctic and Antarctic ecosystems has also been linked to reactions of gas-phase elemental mercury with gasphase $\mathrm{X}^{\bullet}$ and $\mathrm{XO}^{\bullet}$ (Ebinghaus et al., 2002; Lindberg et al., 2002).

Published by Copernicus GmbH on behalf of the European Geosciences Union. 
Because reactions in the aqueous phase appear to play a large role in the overall chemistry of gaseous reactive halogen species, it is important to understand the reactions that form $X^{*}(\mathrm{aq})$. While many past studies of individual halogen radical reactions in aqueous solution have used flash photolysis and pulse radiolysis, these techniques require equipment that is rather specialized and expensive. An alternative approach is use of a chemical probe in conjunction with competition kinetics, a technique that has been used in the past to measure hydroxyl radical $\left({ }^{\bullet} \mathrm{OH}\right)$ in seawater, cloud water, fog water, and on ice (Zhou and Mopper, 1990; Zepp et al., 1992; Faust and Allen, 1993; Arakaki and Faust, 1998; Anastasio and McGregor, 2001; Chu and Anastasio, 2005). The goal of this work was to create an analogous technique to measure aqueous reactive halogen species using allyl alcohol (2propene-1-ol), which reacts with $\mathrm{X}^{*}(\mathrm{aq})$ to form brominated or chlorinated diols. As part of this we have developed a kinetic model, based on known halide radical chemistry and our experimental results, in order to test the ability of our technique to determine $X^{*}(\mathrm{aq})$. The first part of this work, described here, is focused on the development of the technique for aqueous solutions containing only bromide. In a companion paper ("Part 2"; Anastasio and Matthew, 2006) we discuss the method development and validation in solutions containing either chloride or both bromide and chloride.

\section{Experimental}

\subsection{Selection of chemical probe and overview of technique}

In this method $\mathrm{X}^{*}(\mathrm{aq})$ species (where $\mathrm{X}=\mathrm{Br}$ or $\mathrm{Cl}$ ) react with allyl alcohol to form halogenated diols that are then quantified. We chose allyl alcohol (AA) as the probe because: i) it has a relatively high water solubility; ii) the double bond serves as the site of reaction for $\mathrm{X}^{*}(\mathrm{aq})$, leading to the formation of stable halogenated products that are commercially available; iii) a number of rate constants for reactions of $X^{*}(\mathrm{aq})$ with AA have been reported; and v) AA does not absorb wavelengths of light present in the troposphere (i.e., above $290 \mathrm{~nm}$ ). Chemistry in our experiments is initiated by photolysis of hydrogen peroxide $\left(\mathrm{H}_{2} \mathrm{O}_{2}\right)$, forming - $\mathrm{OH}$ that oxidizes $\mathrm{Br}^{-}$to form $\mathrm{Br}^{*}(\mathrm{aq})$, which in turn adds to AA to form 3-bromo-1,2-propanediol (3BPD) (Fig. 1a). Figure $1 \mathrm{~b}$ illustrates the major reactions that form the reactive bromide species $\left(\mathrm{Br}^{*}(\mathrm{aq})\right)$ in our experiments. While $\mathrm{Br}^{\bullet}, \mathrm{Br}_{2}$, and $\mathrm{HOBr}$ are the dominant sources of 3BPD under our conditions, their relative contributions depend upon their steady-state concentrations, which depend upon experimental parameters such as $\mathrm{pH},\left[\mathrm{Br}^{-}\right]$, and [AA]. Finally, while our technique can determine reactive bromide and chloride species, it is not currently suitable for iodine because iodinated diols are extremely unstable in aqueous solution.

We developed this reactive halogen technique by first performing a series of increasingly complex experiments and using the results to build and test a kinetic model of the ${ }^{\bullet} \mathrm{OH}-$ initiated oxidation of bromide in the presence of our probe. In these experiments we varied several different parameters $\left(\mathrm{pH},\left[\mathrm{Br}^{-}\right]\right.$, and $\left.[\mathrm{AA}]\right)$ while measuring three endpoints: i) the steady-state concentration of hydroxyl radical $\left(\left[^{\bullet} \mathrm{OH}\right]\right)$, ii) the rate of allyl alcohol loss $\left(R_{L}^{\mathrm{AA}}\right)$, and iii) the rate of 3BPD formation $\left(R_{F}^{3 \mathrm{BPD}}\right)$. We then used the kinetic model developed from these experiments to evaluate the overall chemical probe technique, and a series of three data treatments, under a range of experimental conditions.

\subsection{Experimental conditions and techniques}

\subsubsection{General experimental parameters}

$\mathrm{NaBr}(99.99 \%)$ and $\mathrm{H}_{2} \mathrm{SO}_{4}$ (Optima) were from Aldrich and Fisher, respectively; all other reagents were A.C.S. reagent grade or better. Type I reagent grade water $(\geq 18.2 \mathrm{M} \Omega-\mathrm{cm})$ was obtained from a Millipore Milli-Q Plus system. Illumination solutions contained $1.0 \mathrm{mM} \mathrm{H}_{2} \mathrm{O}_{2}$ (Fisher) as a photochemical source of $\bullet$ OH (and $\mathrm{HO}_{2}^{\bullet}$ via the ${ }^{\bullet} \mathrm{OH}+\mathrm{H}_{2} \mathrm{O}_{2}$ reaction); $\mathrm{H}_{2} \mathrm{O}_{2}$ stock concentrations were verified daily by UV absorbance $\left(\varepsilon_{240}=38.1 \mathrm{M}^{-1} \mathrm{~cm}^{-1}\right.$; Miller and Kester, 1988). Sample $\mathrm{pH}$ values were adjusted using $1.0 \mathrm{M} \mathrm{H}_{2} \mathrm{SO}_{4}$ (for $\mathrm{pH}$ $\leq 5.5$ ) or a solution of $1.0 \mathrm{mM}$ sodium tetraborate and $0.30 \mathrm{M}$ $\mathrm{NaOH}(\mathrm{pH}>5.5)$. Based on control experiments where only sodium hydroxide was used to adjust the $\mathrm{pH}$, the presence of borate had no effect on chemistry in our solutions.

Samples $(\sim 23 \mathrm{~mL})$ were air-saturated and were illuminated with $313 \mathrm{~nm}$ light from a $1000 \mathrm{~W} \mathrm{Hg} / \mathrm{Xe}$ monochromatic system (Arakaki et al., 1995) in closed $5 \mathrm{~cm}$ quartz cells (FUV quartz, Spectrocell) that were stirred continuously and maintained at $20^{\circ} \mathrm{C}$. Over the course of illumination (typically $1 \mathrm{~h}$ ), aliquots of sample were removed at specified times (every $\sim 10-15 \mathrm{~min}$ ) and analyzed for ${ }^{\bullet} \mathrm{OH}$, AA, or 3BPD; a total of $<15 \%$ of the initial volume of sample was removed during any experiment. In order to calculate photolysis rates the actinic flux was measured during each experiment using 2-nitrobenzaldehyde actinometry (Anastasio et al., 1994). Illuminated controls showed that there was no loss of AA and no formation of 3BPD in samples that did not contain $\mathrm{H}_{2} \mathrm{O}_{2}$, regardless of whether bromide was present. Separate experiments on solutions containing $1.0 \mathrm{mM} \mathrm{H}_{2} \mathrm{O}_{2}$, $0.80 \mathrm{mM} \mathrm{Br}^{-}$, and 3BPD showed that there was no loss of 3BPD during illumination. Dark controls were prepared by placing $\sim 4 \mathrm{~mL}$ of sample in a $1 \mathrm{~cm}$ airtight quartz cell, placing it in a dark cell chamber $\left(20^{\circ} \mathrm{C}\right.$, stirred $)$, and taking a sample at the final illumination time point. Rates of 3BPD formation in the dark controls were generally negligible and were subtracted from the corresponding illuminated rates.

\subsubsection{Measurements of ${ }^{\bullet} \mathrm{OH}$, allyl alcohol, and 3BPD}

The rate of formation, lifetime, and steady-state concentration of $\bullet \mathrm{OH}$ were measured using the formation of 
m-hydroxybenzoic acid (m-HBA) from the reaction of ${ }^{\bullet} \mathrm{OH}$ with a benzoic acid (BA) chemical probe (Zhou and Mopper, 1990). m-HBA was measured on an isocratic highpressure liquid chromatographic (HPLC) system consisting of a Shimadzu LC10-AT pump and SPD-10AV UV/Vis detector with a Keystone Scientific C-18 Beta Basic reversephase column $(250 \times 3 \mathrm{~mm}, 5 \mu \mathrm{m}$ bead $)$ and guard column (Anastasio and McGregor, 2001). Allyl alcohol loss was measured on the same HPLC system using an eluent of $5 \%$ acetonitrile $/ 95 \% \mathrm{H}_{2} \mathrm{O}$ at a flow rate of $0.60 \mathrm{~mL} \mathrm{~min}^{-1}$ and a detection wavelength of $200 \mathrm{~nm}$. Concentrations of AA were determined based on calibration standards made in Milli-Q water run during the day of an experiment; the addition of $\mathrm{Br}^{-}$had no significant effect on AA quantification. Calibration curves were very linear (with $R^{2}$ values typically $>0.99$ ) and values for replicate injections generally agreed within $5 \%$. We did not determine a detection limit for the AA technique, but we could readily measure concentrations near $2 \mu \mathrm{M}$ in our laboratory solutions. 3bromo-1,2-propanediol (3BPD) was extracted and analyzed by GC-ECD as detailed previously (Matthew and Anastasio, 2000) with minor changes as described in the supplementary material (http://www.atmos-chem-phys.net/6/2423/ 2006/acp-6-2423-2006-supplement.pdf; Sect. S.1; note that section, equation or table numbers with the prefix "S" are all supplementary material).

The rate of 3BPD formation in a given experiment was determined as the slope of a linear regression in a plot of [3BPD] versus illumination time. (The same procedure is used for determining formation rates for the chlorinated diol in Part 2.) The rate of loss of allyl alcohol in a given experiment (i.e., at a given initial AA concentration) was determined by first taking a linear regression of $\ln \left([\mathrm{AA}]_{t} /[\mathrm{AA}]_{0}\right)$ versus illumination time, where $[\mathrm{AA}]_{t}$ is the concentration at time $t$ and $[\mathrm{AA}]_{0}$ is the initial concentration in the experiment. The slope of this plot is the negative of the pseudo first-order rate constant for AA loss. We multiplied this rate constant by $[\mathrm{AA}]_{0}$ to determine the initial rate of AA loss for each solution.

\subsubsection{Kinetic models}

The program Acuchem (Braun et al., 1988) was used to model aqueous halide radical chemistry in the illuminated solutions. The complete kinetic model used here (" $\mathrm{Br}^{-}$Full Model") is composed of 87 reactions that describe the photolysis of $\mathrm{H}_{2} \mathrm{O}_{2}$ to form hydroxyl radical and the subsequent - OH-initiated reactions with bromide and allyl alcohol as outlined in Figs. 1a and b. All of the reactions in the model are described in Tables S1-S3. For a given model run the $\mathrm{pH}$ was fixed at the experimentally measured value. One key parameter that we used to fit the model to the experimental data was the set of reactions of reactive bromine species $\left(\mathrm{Br}^{*}(\mathrm{aq})\right)$ with AA to form 3BPD and other products:

$\mathrm{Br}^{*}(\mathrm{aq})+\mathrm{AA} \rightarrow 3 \mathrm{BPD}$

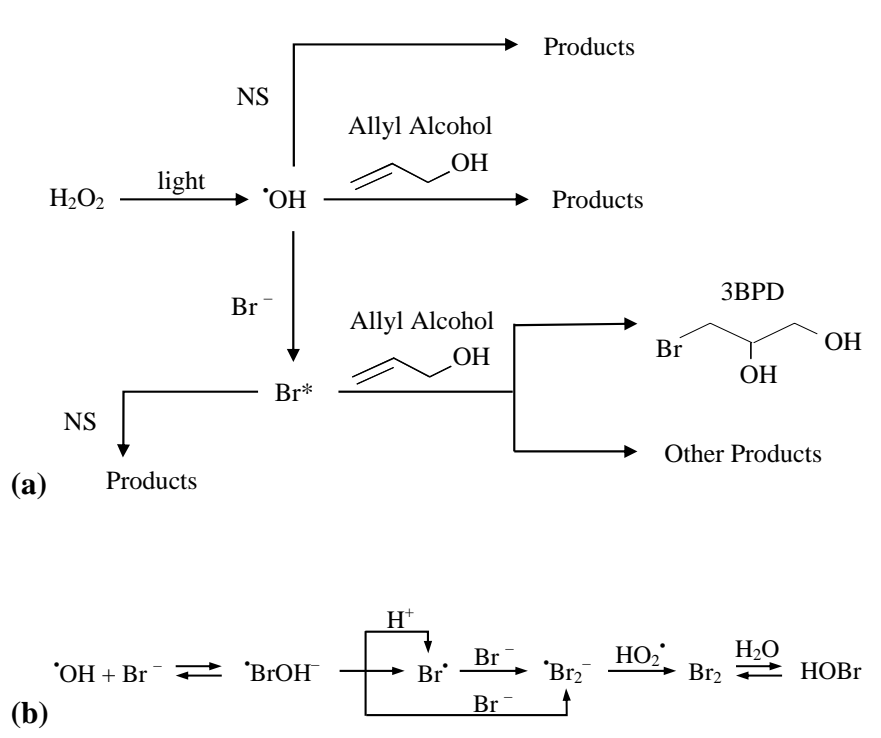

Fig. 1. (a) Simplified scheme showing the formation of reactive bromine species $\left(\mathrm{Br}^{*}\right)$ and their reaction with allyl alcohol (AA) to form 3-bromo-1,2-propanediol (3BPD). Note that AA also consumes ${ }^{\bullet} \mathrm{OH}$, thereby decreasing the rates of formation of $\mathrm{Br}^{*}(\mathrm{aq})$ and 3BPD (i.e., the "AA effect"). NS=natural scavengers, i.e., all other sinks (including $\mathrm{H}_{2} \mathrm{O}_{2}$ ) for ${ }^{\bullet} \mathrm{OH}$ and $\mathrm{Br}^{*}(\mathrm{aq}$ ). (b) An overview of the major reactions that form reactive bromine species $(\mathrm{Br} *)$ in our solutions. Note that the reactions are not balanced; see the supplementary material (http://www.atmos-chem-phys.net/ 6/2423/2006/acp-6-2423-2006-supplement.pdf; Tables S1-S3) for a complete list of the balanced reactions.

$\mathrm{Br}^{*}(\mathrm{aq})+\mathrm{AA} \rightarrow$ other products

While the total rate constant (i.e., $k_{\mathrm{R} 1}+k_{\mathrm{R} 2}$ ) for reaction of a given $\mathrm{Br}^{*}(\mathrm{aq})$ species with $\mathrm{AA}$ was fixed based on literature data, we chose the relative sizes of $k_{\mathrm{R} 1}$ and $k_{\mathrm{R} 2}$ to fit the experimental data. In this way we determined $Y_{i}^{3 \mathrm{BPD}}$, the yield of 3BPD from the reaction of $\mathrm{Br}^{*}(\mathrm{aq})$ species $i$ with AA:

$Y_{i}^{3 \mathrm{BPD}}=\frac{k_{\mathrm{R} 1}}{k_{\mathrm{R} 1}+k_{\mathrm{R} 2}}$

Rate constants for each $\mathrm{Br}^{*}(\mathrm{aq})$ species with $\mathrm{AA}$, and the corresponding yields of 3BPD, are listed in Table S3 of the supplementary material (http://www.atmos-chem-phys. net/6/2423/2006/acp-6-2423-2006-supplement.pdf).

\subsection{Overview of competition kinetics}

Performing competition kinetics experiments with a chemical probe allows quantitative determination of the steadystate concentration ([i]), rate of formation $\left(R_{F}^{i}\right)$, and lifetime $\left(\tau_{i}\right)$ of a reactive species $i$. Although experiments are conducted in the presence of varying concentrations of the probe compound, the values for $[i], R_{F}^{i}$ and $\tau_{i}$ obtained from the method are for conditions where the probe is not present (i.e., 


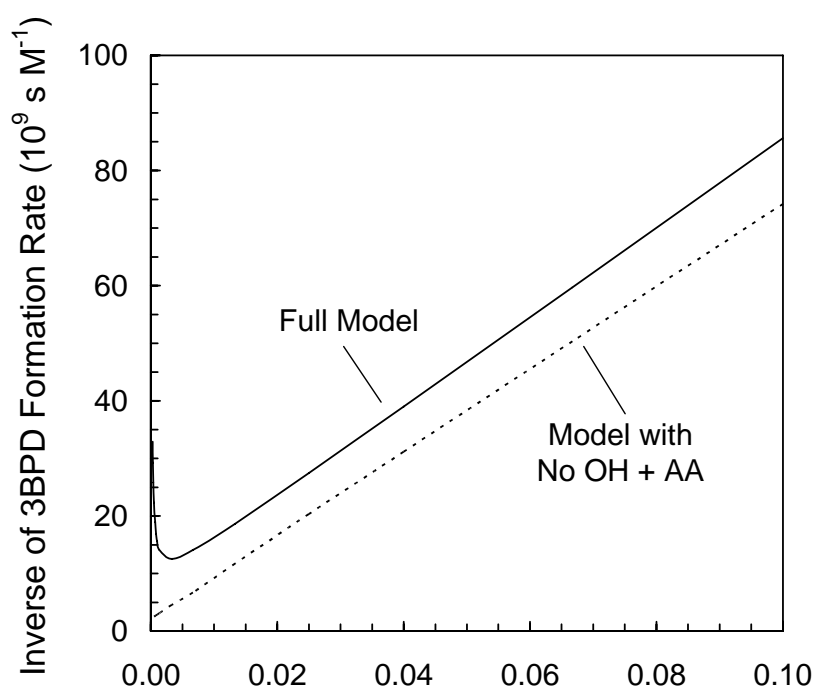

Inverse of Allyl Alcohol Concentration $\left(10^{6} \mathrm{M}^{-1}\right)$

Fig. 2. Inverse plots for $1 / R_{F \text {,tot }}^{3 \mathrm{BPD}}$ from data generated from two different models under the same conditions $\left(0.80 \mathrm{mM} \mathrm{Br}^{-}, 10\right.$ $1000 \mu \mathrm{M}$ AA, $\mathrm{pH}$ 5.3). The solid line was generated from the " $\mathrm{Br}^{-}$ Full Model" and illustrates the nonlinear behaviour associated with increasing [AA] (i.e., decreasing 1/[AA]). The dashed line was generated from the "No ${ }^{\bullet} \mathrm{OH}+\mathrm{AA}$ Model", which is identical to the $\mathrm{Br}^{-}$Full Model except that AA is not allowed to react with ${ }^{\bullet} \mathrm{OH}$. The difference in the two lines illustrates the impact of the "AA effect".

[probe] $=0$ ). For example, ${ }^{\bullet} \mathrm{OH}$ kinetics in solution can be measured by determining the rate of $\mathrm{m}$-HBA formation from the reaction of $\bullet \mathrm{OH}$ with added benzoic acid (BA) (Zhou and Mopper, 1990; Anastasio and McGregor, 2001). Plotting the inverse of the rate of $\mathrm{m}$-HBA formation as a function of the inverse of the BA concentration (i.e., making an "inverse plot") produces a straight line; the slope and y-intercept of this line are then used to calculate $\left[{ }^{\bullet} \mathrm{OH}\right], R_{F}^{\mathrm{OH}}$, and $\tau_{\mathrm{OH}}$. A key feature of this technique is that the addition of BA does not affect the rate of ${ }^{\bullet} \mathrm{OH}$ formation and, therefore, the inverse plot is linear over the entire $[\mathrm{BA}]$ range.

In contrast, in the technique described here the formation rate of the reactive bromine species $\left(\mathrm{Br}^{*}(\mathrm{aq})\right)$ is affected by the addition of the probe compound, allyl alcohol (AA). As shown in Fig. 1a, in the absence of allyl alcohol ${ }^{\bullet} \mathrm{OH}$ reacts with either natural scavengers (NS) or with $\mathrm{Br}^{-}$to form $\mathrm{Br}^{*}(\mathrm{aq})$. AA added to the solution reacts with $\mathrm{Br}^{*}(\mathrm{aq})$ to form 3BPD, but it is also a sink for ${ }^{\bullet} \mathrm{OH}$, which lowers the steady-state ${ }^{\bullet} \mathrm{OH}$ concentration and therefore lowers the rate of $\mathrm{Br}^{*}(\mathrm{aq})$ formation. As long as $\mathrm{Br}^{-}$is the dominant sink for ${ }^{\bullet} \mathrm{OH}$, the decrease in the rate of $\mathrm{Br}^{*}(\mathrm{aq})$ formation due to AA addition is relatively small, and the rate of formation of 3BPD $\left(R_{F}^{3 \mathrm{BPD}}\right)$ rises with increasing $\mathrm{AA}$ concentrations. However, once AA becomes the dominant sink for ${ }^{\bullet} \mathrm{OH}$, the formation rates of $\mathrm{Br}^{*}(\mathrm{aq})$ and $3 \mathrm{BPD}$ both decrease substantially.

This "AA effect" has two major impacts on the "inverse plot" from the AA competition kinetics experiment (i.e., $1 / R_{F}^{3 \mathrm{BPD}}$ vs. 1/[AA]). As illustrated in Fig. 2, the first effect is that at high AA concentrations, the probe becomes the dominant sink for ${ }^{\bullet} \mathrm{OH}$ and the rate of 3BPD formation slows dramatically, resulting in a quick increase in $1 / R_{F}^{3 \mathrm{BPD}}$ (i.e., the plot is non-linear at high [AA]). The second effect is more subtle, but also important. Even though the inverse plot may not be linear over the entire range of $1 /[\mathrm{AA}]$, the data are linear at low values of [AA] (i.e., high values of $1 /[\mathrm{AA}])$ where AA is a minor sink for ${ }^{\bullet} \mathrm{OH}$. However, even within this linear range, the presence of $\mathrm{AA}$ decreases the rate of $\mathrm{Br}^{*}(\mathrm{aq})$ formation, changing the slope and $\mathrm{y}$-intercept of the inverse plot from what they would be if ${ }^{\bullet} \mathrm{OH}$ did not react with $\mathrm{AA}$ (Fig. 2). For the $\mathrm{pH}$ and $\left[\mathrm{Br}^{-}\right]$values used for our experiments, the effect on the slope is very small but the effect on the y-intercept can, under certain conditions, be large enough to considerably bias the experimental results. However, as discussed below, in many cases corrections can be made for these biases.

While in theory the relationship between the rate of 3BPD formation from all $\mathrm{Br} *(\mathrm{aq})$ species and the concentration of added AA can be derived mathematically from the series of elementary reactions that describe the experimental system, in practice this can be extremely difficult. As described in the supplementary material (http://www.atmos-chem-phys.net/ 6/2423/2006/acp-6-2423-2006-supplement.pdf; Sect. S.2), we can derive this equation for $\mathrm{Br}^{\bullet}$ in the case where this radical is the dominant source of 3BPD:

$$
\begin{aligned}
& \frac{1}{R_{F, \text { tot }}^{3 \mathrm{BPD}}}=a+\frac{b}{[\mathrm{AA}]}+c[\mathrm{AA}] \\
& a=\frac{\left(k_{\mathrm{OH}}^{\mathrm{AA}} k_{\mathrm{Br}}^{\prime \mathrm{NS}}+k_{\mathrm{Br}}^{\mathrm{AA}} k_{\mathrm{OH}}^{\prime \mathrm{NS}}\right) F_{\mathrm{Br}}^{3 \mathrm{BPD}}}{R_{F}^{\mathrm{Br}} Y_{\mathrm{Br}}^{3 \mathrm{BPD}} k_{\mathrm{Br}}^{\mathrm{AA}} k_{\mathrm{OH}}^{\prime \mathrm{NS}}} \\
& b=\frac{F_{\mathrm{Br}}^{3 \mathrm{BPD}}}{Y_{\mathrm{Br}}^{3 \mathrm{BPD}} k_{\mathrm{Br}}^{\mathrm{AA}}\left[\mathrm{Br}^{\bullet}\right]} \\
& c=\frac{k_{\mathrm{OH}}^{\mathrm{AA}} F_{\mathrm{Br}}^{3 \mathrm{BPD}}}{R_{F}^{\mathrm{OH}} Y_{\mathrm{Br}}^{3 \mathrm{BPD}} k_{\mathrm{OH}}^{\mathrm{Br}-}\left[\mathrm{Br}^{-}\right] Y_{\mathrm{OH}}^{\mathrm{Br}}}=\frac{k_{\mathrm{OH}}^{\mathrm{AA}} F_{\mathrm{Br}}^{3 \mathrm{BPD}}}{k_{\mathrm{OH}}^{\prime \mathrm{NS}} Y_{\mathrm{Br}}^{3 \mathrm{BPD}} R_{F}^{\mathrm{Br}}}
\end{aligned}
$$

where $R_{F \text {, tot }}^{3 \mathrm{BPD}}$ is the total rate of 3BPD formation from all species, $F_{\mathrm{Br}}^{3 \mathrm{BPD}}$ is the fraction of 3BPD that is formed from the reaction of $\mathrm{Br}^{\bullet}$ with $\mathrm{AA}$ (Sect. S.4), $Y_{\mathrm{Br}}^{3 \mathrm{BPD}}$ is the yield of 3BPD from the reaction of $\mathrm{Br}^{\bullet}$ with $\mathrm{AA}$ (Eq. 1), and $k_{m}^{n}$ is the rate constant for the reaction of species $m$ with $n$. The variables $a, b$, and $c$ are determined by fitting the experimental data $\left(R_{F \text {, tot }}^{3 \mathrm{BPD}}\right.$ as a function of [AA]) to Eq. (S13) using a nonlinear least-squares technique (Sigmaplot, version 4.0). 
By rearranging the $b$ and $c$ terms it is possible to solve for $\left[\mathrm{Br}^{\bullet}\right], R_{F}^{B r}$, and $\tau_{B r}$ :

$\left[\mathrm{Br}^{\bullet}\right]=\frac{F_{\mathrm{Br}}^{3 \mathrm{BPD}}}{b Y_{\mathrm{Br}}^{3 \mathrm{BPD}} k_{\mathrm{Br}}^{\mathrm{AA}}}$

$R_{F}^{\mathrm{Br}}=\frac{k_{\mathrm{OH}}^{\mathrm{AA}} F_{\mathrm{Br}}^{3 \mathrm{BPD}}}{c k_{\mathrm{OH}}^{\prime \mathrm{NS}} Y_{\mathrm{Br}}^{3 \mathrm{BPD}}}$

$\tau_{\mathrm{Br}}=\frac{c k_{\mathrm{OH}}^{\mathrm{NS}}}{b k_{\mathrm{OH}}^{\mathrm{AA}} k_{\mathrm{Br}}^{\mathrm{AA}}}=\frac{\left[\mathrm{Br}^{\bullet}\right]}{R_{F}^{\mathrm{Br}}}$

These $\mathrm{Br}^{\bullet}$ kinetic terms are determined by using the nonlinear least squares fitted values for $a, b$, and $c$ in conjunction with $F_{\mathrm{Br}}^{3 \mathrm{BPD}}, Y_{\mathrm{Br}}^{3 \mathrm{BPD}}$, and $k_{m}^{n}$.

Because this kinetic derivation takes into account the effect of AA on $\left[{ }^{\bullet} \mathrm{OH}\right]$ and the formation of $\mathrm{Br}^{\bullet}$, Eq. (S13) accounts for the "AA effect". Although similar expressions can be derived for $\mathrm{Br}_{2}$ and $\mathrm{HOBr}$, these expressions contain several terms that are currently unknown and that are hard to estimate (e.g., the formation rate and concentration of $\mathrm{HO}_{2}^{*}$; Sect. S.2). Because of these unknown parameters, using equations analogous to Eq. (S13) to determine the $\mathrm{Br}_{2}$ and $\mathrm{HOBr}$ kinetics is currently not feasible.

However, the kinetics of $\mathrm{Br}_{2}$ and $\mathrm{HOBr}$ can be measured by working in the linear range of the $1 / R_{F \text {, tot }}^{3 \mathrm{BPD}}$ versus $1 /$ [AA] plot where AA concentrations are low (Fig. 2). In this linear range, we assume that the low AA concentrations have little effect on $\left[{ }^{\bullet} \mathrm{OH}\right]$ and on the rates of $\mathrm{Br}^{*}(\mathrm{aq})$ and $3 \mathrm{BPD}$ formation (i.e., the AA effect is minimized). In this case Eq. (S13) can be simplified to (Sect. S.3):

$\frac{1}{R_{F, t o t}^{3 \mathrm{BPD}}}=a^{\prime}+\frac{b^{\prime}}{[\mathrm{AA}]}$

where $a^{\prime}$ and $b^{\prime}$ are the y-intercept and slope of the linear portion of the inverse plot, respectively:

$a^{\prime}=\frac{F_{i}^{3 \mathrm{BPD}}}{Y_{i}^{3 \mathrm{BPD}} R_{F}^{i}}$
$b^{\prime}=\frac{F_{i}^{3 \mathrm{BPD}}}{Y_{i}^{3 \mathrm{BPD}} k_{i}^{\mathrm{AA}}[i]}$

The $a^{\prime}$ and $b^{\prime}$ terms can be rearranged to solve for $[i], R_{F}^{i}$, and $\tau_{i}$ as follows:

$$
\begin{aligned}
& {[i]=\frac{F_{i}^{3 \mathrm{BPD}}}{b^{\prime} Y_{i}^{3 \mathrm{BPD}} k_{i}^{\mathrm{AA}}}} \\
& R_{F}^{i}=\frac{F_{i}^{3 \mathrm{BPD}}}{a^{\prime} Y_{i}^{3 \mathrm{BPD}}} \\
& \tau_{i}=\frac{a^{\prime}}{b^{\prime} k_{i}^{\mathrm{AA}}}=\frac{[i]}{R_{F}^{i}}
\end{aligned}
$$

These equations are applicable for any $\mathrm{Br}^{*}(\mathrm{aq})$ species $i$ (e.g., $\mathrm{Br}^{\circ}, \mathrm{Br}_{2}$, and $\mathrm{HOBr}$ ) and are analogous to those derived for the ${ }^{\bullet} \mathrm{OH}$ system with $\mathrm{BA}$ as the probe (Zhou and Mopper, 1990; Anastasio and McGregor, 2001).

Using the linear Eq. (S25) instead of the more complex Eq. (S13) implicitly assumes that AA has only a minor effect upon ${ }^{\bullet} \mathrm{OH}$ (and, therefore on $\mathrm{Br}^{*}(\mathrm{aq})$ and $3 \mathrm{BPD}$ formation) in the linear portion of the inverse plot. The advantage of this assumption is that it allows Eq. (S25) to be broadly applied to all reactive Br*(aq) species $i$ (Sect. S.3). The disadvantage is that, while it generally has a minor effect on the determination of $[i]$, it can introduce large (though often correctable) errors in the determination of $R_{F}^{i}$ and $\tau_{i}$.

\section{Results and discussion}

3.1 Experiments with only hydrogen peroxide and allyl alcohol

As a first step in examining the probe chemistry, we illuminated $\mathrm{pH} 5.5$ solutions containing $1.0 \mathrm{mM} \mathrm{H}_{2} \mathrm{O}_{2}$ with and without AA to test whether we could correctly model - $\mathrm{OH}$ steady-state concentrations. In a $1.0 \mathrm{mM} \mathrm{H}_{2} \mathrm{O}_{2}$ solution, the experimentally measured $\left[{ }^{\circ} \mathrm{OH}\right]( \pm 1 \mathrm{SE})$ was $(2.1 \pm 0.1) \times 10^{-13} \mathrm{M}$, in good agreement with the model value of $2.8 \times 10^{-13} \mathrm{M}$ (the relative percent difference (RPD) between these values is $29 \%$ ). When $75 \mu \mathrm{M}$ of allyl alcohol was added to a $1.0 \mathrm{mM} \mathrm{H}_{2} \mathrm{O}_{2}$ solution, the measured value for $\left[{ }^{\bullet} \mathrm{OH}\right]( \pm 1 \mathrm{SE})$ dropped to $(1.3 \pm 0.1) \times 10^{-14} \mathrm{M}$, in good agreement with the modeled value of $1.7 \times 10^{-14} \mathrm{M}$ ( $\mathrm{RPD}=27 \%$ ).

In the second set of experiments, we measured the rate of loss of $\mathrm{AA}\left(R_{L}^{\mathrm{AA}}\right)$ in $\mathrm{pH} 5.5$ solutions containing $1.0 \mathrm{mM}$ $\mathrm{H}_{2} \mathrm{O}_{2}$ and $15-1000 \mu \mathrm{M}$ allyl alcohol. As seen in Fig. 3, $R_{L}^{\mathrm{AA}}$ increases rapidly between 15 and $150 \mu \mathrm{M}$ AA but is relatively constant at higher concentrations where AA is the dominant sink for ${ }^{\bullet} \mathrm{OH}$. Modeled rates of loss are within the experimental errors of the measured values out to $300 \mu \mathrm{M}$ AA, but are overpredicted at higher [AA]. An additional experiment performed at $\mathrm{pH} 3.0(75 \mu \mathrm{M} \mathrm{AA})$ gave nearly identical results to the $\mathrm{pH} 5.5$ experiment and was in good agreement with the model (RPD=3\%, Fig. 3).

There are two mechanisms for AA loss in our model: direct reaction between AA and oxidants (e.g., $\bullet \mathrm{OH}$, Reaction 70, Table S3) and polymerization reactions involving AA radicals (formed from the reaction of ${ }^{\bullet} \mathrm{OH}$ or $\mathrm{Br}^{*}$ with AA) and another molecule of AA (e.g., Reactions 71-73, Table S3). Comparing the calculated rate of $\bullet \mathrm{OH}$ formation in these experiments $\left(0.43 \mu \mathrm{M} \mathrm{min}{ }^{-1}\right)$ with the measured rate of AA loss in the plateau of Fig. $3(0.69 \mu \mathrm{M}$ $\mathrm{min}^{-1}$ ), indicates that approximately $40 \%$ of AA loss is due to polymerization reactions in this region. Although polymerization during free-radical additions is well established (March, 1992), we were unable to find rate constants for the 


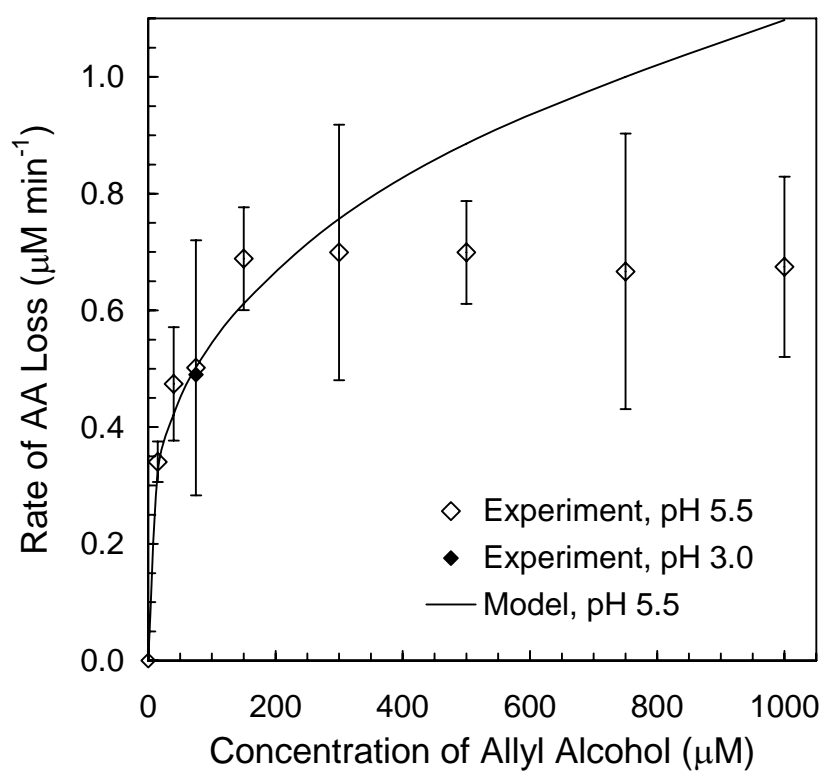

Fig. 3. Rate of allyl alcohol loss $\left(R_{L}^{\mathrm{AA}}\right)$ as a function of $[\mathrm{AA}]$ in illuminated $(313 \mathrm{~nm})$ aqueous solutions ( $\mathrm{pH} 5.5)$ containing only AA and $1.0 \mathrm{mM} \mathrm{H}_{2} \mathrm{O}_{2}$. The open diamonds are experimental values with error bars representing $90 \%$ confidence intervals $(\mathrm{CI})$, based on the standard error of the slope from a plot of AA loss at each [AA]. The line is the model result using the $\mathrm{Br}^{-}$Full Model with $\left[\mathrm{Br}^{-}\right]=0$. The filled diamond at $75 \mu \mathrm{M} \mathrm{AA}$ is the measured rate of AA loss at $\mathrm{pH} 3.0$.

polymerization of aqueous AA. The good agreement in the modeled and measured values for AA loss at lower AA concentrations indicate that our modeled rate constants for polymerization are reasonable at most of the AA concentrations we employed, but not at the higher concentrations. As shown later, this overestimate of allyl alcohol loss at high [AA] does not affect the model predictions of 3BPD formation or the calculated $\mathrm{Br}^{*}(\mathrm{aq})$ kinetics.

\section{2 ${ }^{\circ} \mathrm{OH}$ measurements in the presence of bromide}

To begin to test and constrain the kinetic model in bromide solutions we first measured the ${ }^{\bullet} \mathrm{OH}$ steady-state concentration in illuminated solutions $\left(1.0 \mathrm{mM} \mathrm{H}_{2} \mathrm{O}_{2}, \mathrm{pH} 5.5\right)$ containing seawater levels of bromide $(0.80 \mathrm{mM}$; Zafiriou et al., 1987) with and without allyl alcohol. In the absence of AA, the measured and modeled values of $\left[{ }^{\bullet} \mathrm{OH}\right]$ were nearly identical $(7.1 \pm 0.2) \times 10^{-15}$ and $7.0 \times 10^{-15} \mathrm{M}$, respectively). In the presence of AA, the RPD between the measured and modeled values of $\left[{ }^{\bullet} \mathrm{OH}\right]$ was $<5 \%$ for experiments with 15 , 40 and $75 \mu \mathrm{M} \mathrm{AA}$ and was $47 \%$ in a solution with $150 \mu \mathrm{M}$ AA. Thus the model does a good to excellent job of representing ${ }^{\bullet} \mathrm{OH}$ chemistry in the presence of bromide.
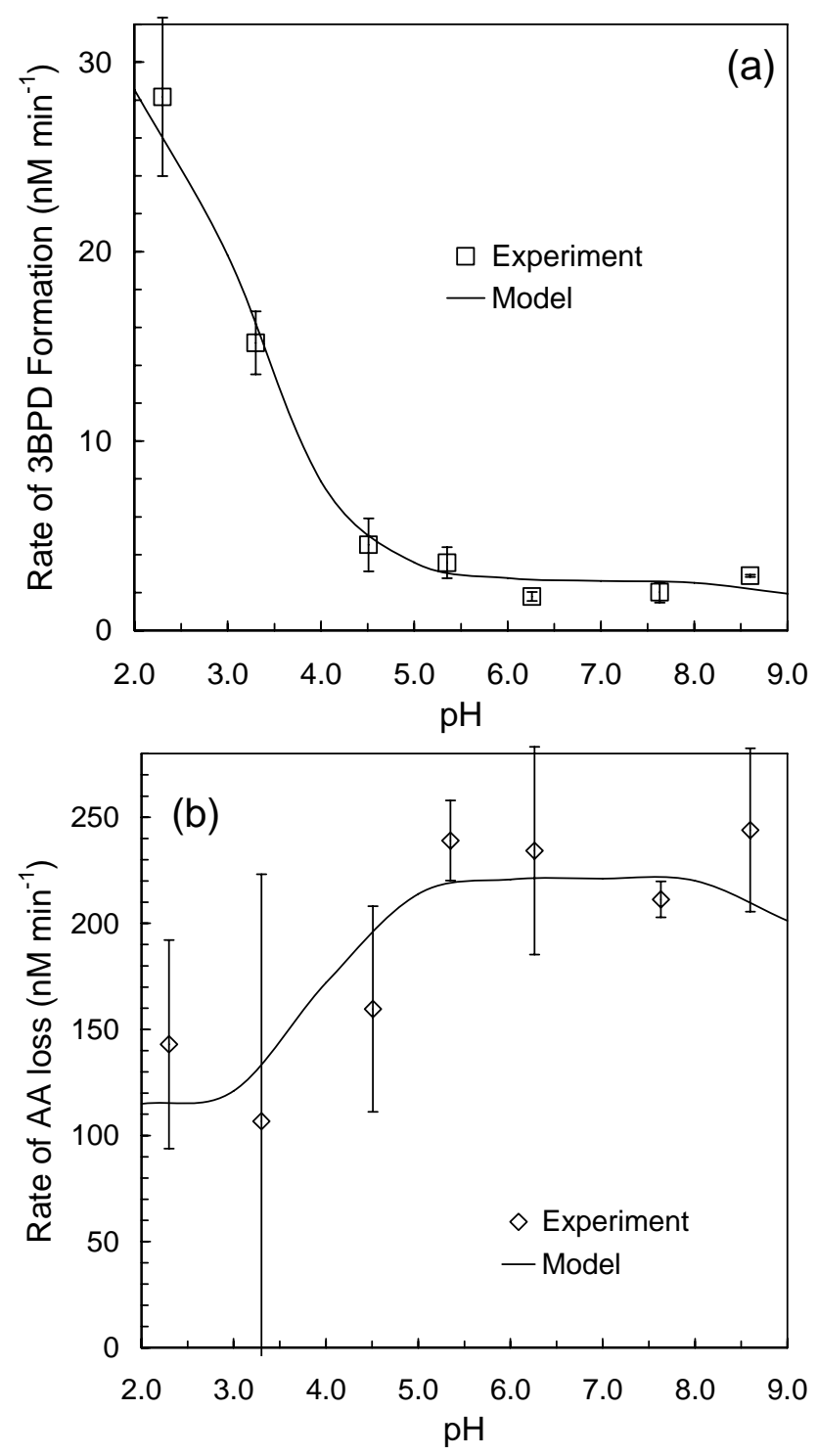

Fig. 4. (a) Rate of 3-bromo-1,2-propanediol (3BPD) formation $\left(R_{F, \text { tot }}^{3 \mathrm{BPD}}\right)$ as a function of $\mathrm{pH}$ in illuminated $(313 \mathrm{~nm})$ aqueous bromide solutions $\left(\left[\mathrm{Br}^{-}\right]=0.80 \mathrm{mM}\right)$ containing $1.0 \mathrm{mM} \mathrm{H}_{2} \mathrm{O}_{2}$ and $75 \mu \mathrm{M}$ AA. The squares are experimental values of $R_{F \text {,tot }}^{3 \mathrm{BPD}}$. Error bars for 3BPD represent the $90 \%$ confidence interval for each point, calculated from the standard error of the slope from plots of 3BPD versus time at each $\mathrm{pH}$. The line is the result from the " $\mathrm{Br}^{-}$Full Model". (b) Rate of AA loss as a function of $\mathrm{pH}$ in the illuminated aqueous bromide solutions described in Fig. 4a. The symbols, line, and error bars are the same as in Fig. 3.

\subsection{Formation of 3BPD $\left(R_{F, \text { tot }}^{3 \mathrm{BPD}}\right)$ and loss of $\mathrm{AA}\left(R_{L}^{\mathrm{AA}}\right)$ as a function of $\mathrm{pH}$}

To build and test our model as a function of $\mathrm{pH}$, we conducted experiments on solutions containing $0.80 \mathrm{mM} \mathrm{NaBr}$, $1.0 \mathrm{mM} \mathrm{H}_{2} \mathrm{O}_{2}$, and $75 \mu \mathrm{M}$ AA over the $\mathrm{pH}$ range of 2.3 to 
8.6. As shown in Figs. $4 \mathrm{a}$ and $\mathrm{b}$, the model correctly describes both $R_{F \text {, tot }}^{3 \mathrm{BPD}}$ and $R_{L}^{\mathrm{AA}}$ over a wide range of $\mathrm{pH}$. Of particular interest is the large increase in the rate of 3BPD formation at low $\mathrm{pH}$ (Fig. 4a), which is caused by the reaction of $\mathrm{HO}_{2}^{\bullet}$ with ${ }^{\bullet} \mathrm{Br}_{2}^{-}$to form $\mathrm{Br}_{2}$ (Fig. 1b), which then reacts with AA to form 3BPD (Matthew et al., 2003).

In our experiments $3 \mathrm{BPD}$ is formed by $\mathrm{Br}^{\circ}, \mathrm{Br}_{2}$, and $\mathrm{HOBr}$, and the relative importance of each species as a source of $3 \mathrm{BPD}$ changes as a function of $\mathrm{pH}$ and other experimental conditions (Sect. S.4). Under the conditions of Fig. $4, \mathrm{Br}_{2}$ is the most important species at low $\mathrm{pH}$ values $(<4)$ while $\mathrm{Br}^{\bullet}$ is most important at higher $\mathrm{pH}$ values. The dibromide radical anion $\left({ }^{\bullet} \mathrm{Br}_{2}^{-}\right)$and tribromide ion $\left(\mathrm{Br}_{3}^{-}\right)$have concentrations that are in the same general range as $\mathrm{Br}^{\bullet}$ and $\mathrm{Br}_{2}$, but their reactions with AA are too slow for them to contribute significantly to 3BPD formation (Reactions 80 and 86 in Table S3). In addition, ${ }^{\bullet} \mathrm{BrOH}^{-}$(Fig. 1b) might also react with AA to form $3 \mathrm{BPD}$, but this reaction appears to be unimportant under all of our experimental conditions and is therefore not included in the kinetic model.

Additional evidence that the model correctly describes aqueous bromide radical chemistry comes from a separate set of experiments conducted in the absence of AA that measured the release of gaseous bromine $\left(\mathrm{Br}^{*}(\mathrm{~g})\right.$, i.e., $\mathrm{Br}_{2}$ or $\mathrm{HOBr}$ ) from air-purged, illuminated solutions $\left(0.10 \mathrm{M} \mathrm{Br}^{-}\right.$, $1.0 \mathrm{mM} \mathrm{H}_{2} \mathrm{O}_{2}$, no AA) (Matthew et al., 2003). As described in this previous paper, the release of $\mathrm{Br}^{*}(\mathrm{~g})$ occurs only during illumination, is strongly dependent on $\mathrm{pH}$, and is very similar to the $\mathrm{pH}$ dependence of 3BPD (Fig. 4a). By setting $[\mathrm{AA}]=0$, and adding reactions for the volatilization of $\mathrm{Br}^{*}(\mathrm{~g})$, the model is able to reproduce these experimental results.

\subsection{Formation of 3BPD $\left(R_{F, \text { tot }}^{3 \mathrm{BPD}}\right)$ and loss of $\mathrm{AA}\left(R_{L}^{\mathrm{AA}}\right)$ as a function of $[\mathrm{AA}]$}

In the final set of five experiments, we measured $R_{F \text {, tot }}^{3 \mathrm{BPD}}$ and $R_{L}^{\mathrm{AA}}$ as a function of [AA] to test the model under conditions of $\mathrm{pH}$ and $\left[\mathrm{Br}^{-}\right]$that are representative of seawater and sea-salt particles (Table 1). As described in Sect. 3.7, these are also the competition kinetics experiments that we used as the final test of the probe technique. In the first experiment we used pH 5.3 solutions containing $0.80 \mathrm{mM} \mathrm{NaBr}$, $0.91 \mathrm{mM} \mathrm{H}_{2} \mathrm{O}_{2}$ and $10-1000 \mu \mathrm{M}$ AA. As shown in Fig. 5a, $R_{F, \text { tot }}^{3 \mathrm{BPD}}$ increases with [AA] up to $\sim 300 \mu \mathrm{M}$ (due to increased scavenging of $\mathrm{Br}^{*}(\mathrm{aq})$ by AA) but declines at higher AA concentrations (because of AA reacting with ${ }^{\bullet} \mathrm{OH}$ ). The model does a good job of explaining observed values of $R_{F \text {, tot }}^{3 \mathrm{BPD}}$ as a function of [AA], with an average RPD between the model and experimental data of $11 \%$ (Table 1). Although $\mathrm{Br}^{\bullet}$ has the lowest steady-state concentration of the important $\mathrm{Br}^{*}(\mathrm{aq})$ species, it is the dominant source of 3BPD in this experiment because of its rapid rate of reaction with AA (Table S3). As shown in Fig. 5b, measured rates of allyl alcohol loss increase with [AA] up to $300 \mu \mathrm{M}$ and are essentially constant at higher $[\mathrm{AA}]$ where the probe scavenges
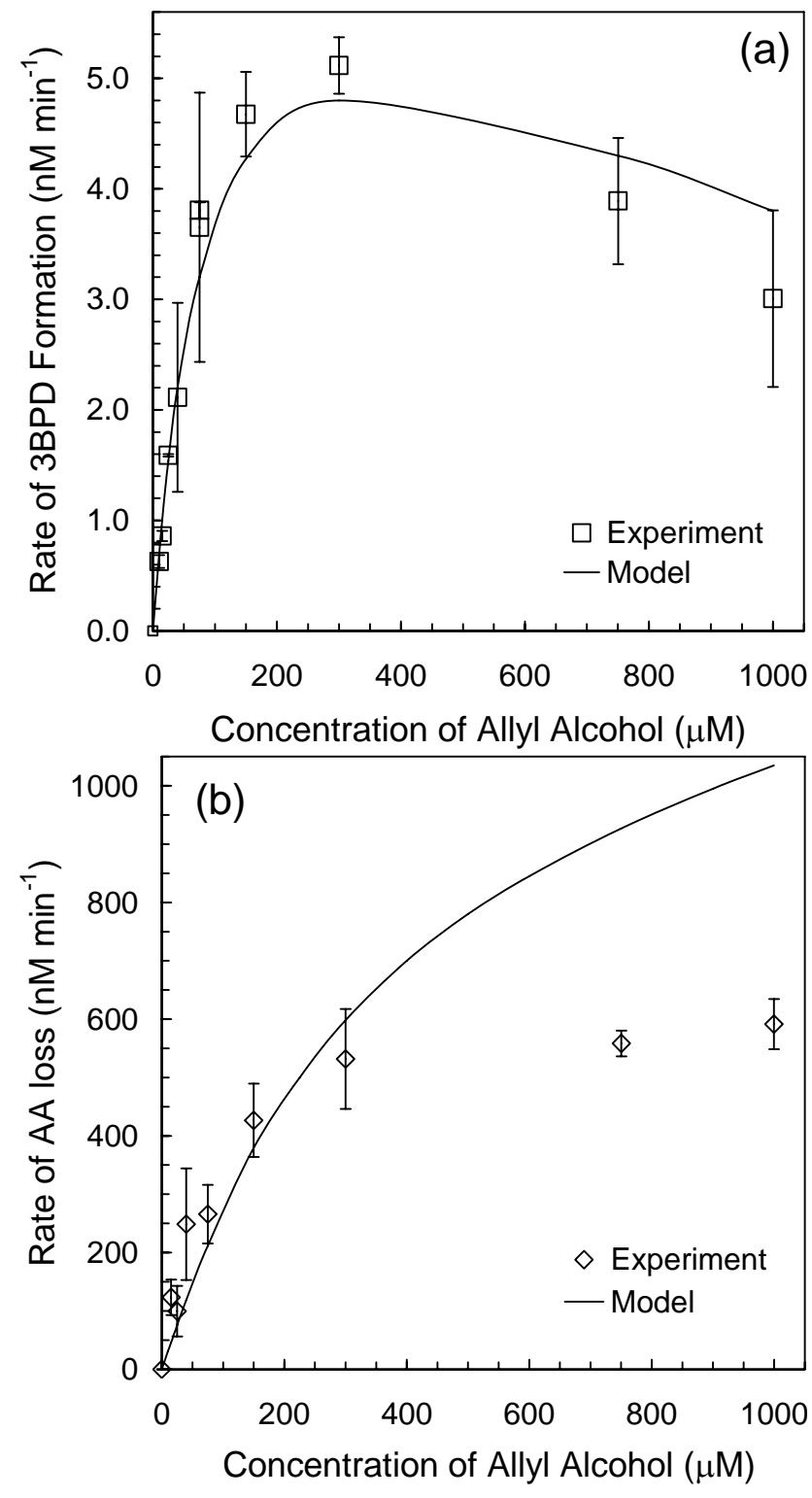

Fig. 5. (a) Experimental and model values of the total rate of 3 bromo-1,2-propanediol (3BPD) formation $\left(R_{F, \text { tot }}^{3 \mathrm{BPD}}\right)$ for competition kinetics Experiment 1 (pH 5.3, $0.80 \mathrm{mM} \mathrm{Br}^{-}, 1.0 \mathrm{mM} \mathrm{H}_{2} \mathrm{O}_{2}, 10$ $1000 \mu \mathrm{M}$ AA, $313 \mathrm{~nm}$ illumination). Symbols, line, and error bars are the same as in Fig. 4a. (b) Experimental and model values of the rate of allyl alcohol loss $\left(R_{L}^{\mathrm{AA}}\right)$ as a function of allyl alcohol concentration for competition kinetics experiment 1 presented in Fig. 5a and Table 1. The symbols, line, and error bars are the same as described in Fig. 3.

most of $\bullet$ OH. The model matches allyl alcohol loss rates at the lower AA concentrations $(<300 \mu \mathrm{M})$ but overestimates $R_{L}^{\mathrm{AA}}$ at higher concentrations, as in the solutions containing only AA and $\mathrm{H}_{2} \mathrm{O}_{2}$ (Fig. 3). As stated previously, this overestimate of AA loss at high [AA] is likely because of our 
Table 1. Parameters for competition kinetic experiments.

\begin{tabular}{|c|c|c|c|c|c|c|c|c|}
\hline \multirow[t]{2}{*}{ Exp \# } & \multirow[t]{2}{*}{$\begin{array}{c}{\left[\mathrm{Br}^{-}\right]} \\
\mathrm{mM}\end{array}$} & \multirow[t]{2}{*}{$\mathrm{pH}$} & \multicolumn{2}{|c|}{$[\mathrm{AA}]$ range tested } & \multicolumn{2}{|c|}{ Linear AA range $^{\mathrm{a}}$} & \multicolumn{2}{|c|}{$\begin{array}{c}\text { Agreement between model } \\
\text { and experiment }{ }^{\mathrm{c}} \text { (Average RPD) }\end{array}$} \\
\hline & & & $\mu \mathrm{M}$ & $\mathrm{n}^{\mathrm{b}}$ & $\mu \mathrm{M}$ & $n^{b}$ & $R_{F, \text { tot }}^{3 \mathrm{BPD}}$ & $R_{L}^{\mathrm{AA}}$ \\
\hline 1 & 0.80 & 5.3 & $10-1000$ & 9 & $10-150$ & 6 & 11 & 43 \\
\hline 2 & 0.80 & 3.0 & $10-8000$ & 11 & $10-110$ & 5 & 41 & 41 \\
\hline 3 & 0.40 & 5.4 & $10-3000$ & 10 & $10-150$ & 6 & 26 & 25 \\
\hline 4 & 0.80 & 8.4 & $10-5000$ & 8 & $10-75$ & 5 & 38 & 40 \\
\hline 5 & 8.0 & 5.3 & $75-500$ & 3 & $75-500$ & 3 & 8 & 14 \\
\hline
\end{tabular}

The concentration of $\mathrm{H}_{2} \mathrm{O}_{2}$ for all experiments was $0.91-1.0 \mathrm{mM}$. The photolysis rate constant for $\mathrm{H}_{2} \mathrm{O}_{2}\left(j_{\mathrm{H} 2 \mathrm{O} 2}\right)$ was $(3.8-4.0) \times 10^{-6} \mathrm{~s}^{-1}$

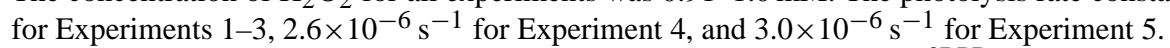

${ }^{a}$ Range of allyl alcohol concentrations over which the inverse plot $\left(1 / R_{F, \text { tot }}^{3 \mathrm{BPD}}\right.$ vs. $\left.1 /[\mathrm{AA}]\right)$ is linear. Note that the linear range can change when the inverse plots are based on 3BPD formation rates from individual species, as is done in treatment $\mathrm{C}$.

$\mathrm{b}$ Number of points sampled within the specified range.

${ }^{c}$ Agreement between the experimental data and model output, calculated as the average of the absolute values of the RPD (relative percent difference) between the model and experimental values of $R_{F \text {, tot }}^{3 \mathrm{BPD}}$ (and $R_{L}^{\mathrm{AA}}$ ) over the entire range of allyl alcohol concentrations. Note that the listed RPD value for $R_{F \text {, tot }}^{3 \mathrm{BPD}}$ is the same as that for $1 / R_{F \text {, tot }}^{3 \mathrm{BPD}}$ (and similarly for $R_{L}^{\mathrm{AA}}$ and $1 / R_{L}^{\mathrm{AA}}$ ).

simplified parameterization of radical-initiated AA polymerization, but this issue does not affect our halogen kinetics results.

The other four experiments in this series were conducted by varying $[\mathrm{AA}]$ in a set of identical solutions where each set had different values for $\mathrm{pH}$ and/or $\left[\mathrm{Br}^{-}\right]$(Table 1). As listed in the column of $F_{i}^{3 \mathrm{BPD}}$ values in Table 2 (see data treatment $\mathrm{B}$ ), the relative contributions of $\mathrm{Br}^{\circ}, \mathrm{Br}_{2}$, and $\mathrm{HOBr}$ to 3BPD formation vary significantly throughout this set of experiments. Despite this, the model does a good to fair job of describing the rates of 3BPD formation and AA loss in these additional experiments, with the best agreement at $\mathrm{pH}$ $\sim 5$. As shown in Table 1, the average RPD values between the measured and modeled values in Experiments 2-5 ranged from $8-41 \%$ for $R_{F \text {, tot }}^{3 \mathrm{BPD}}$ and $14-41 \%$ for $R_{L}^{\mathrm{AA}}$.

\subsection{Competition kinetics: overview and expected values}

Our kinetic model (the " $\mathrm{Br}^{-}$Full Model") was built and constrained using the sets of experiments described above. The good agreement between the modeled and measured values of [ $\left.{ }^{\circ} \mathrm{OH}\right], R_{F \text {, tot }}^{3 \mathrm{BPD}}$ and $R_{L}^{\mathrm{AA}}$ in these experiments gives us confidence that the model reasonably describes the ${ }^{\bullet} \mathrm{OH}-$ mediated oxidation of bromide and subsequent reactions of $\mathrm{Br}^{*}(\mathrm{aq})$ with allyl alcohol. In the next two sections (3.6 and 3.7) we use this model to test the ability of the allyl alcohol chemical probe technique to measure reactive halogen species. This test consists of two major steps. In the first (Sect. 3.6), we examine the validity of the kinetic equations we derived for $[i], R_{F}^{i}$ and $\tau_{i}$ (e.g., Eqs. S17-S19 and S28S30; Sect. 2.3) using "data" generated from simulated model experiments. In the second testing step (Sect. 3.7), we apply the same data treatments to actual data from laboratory com- petition kinetics experiments in order to examine the overall utility of the probe technique for measuring $[i], R_{F}^{i}$ and $\tau_{i}$.

In order to examine whether our derived equations for [i], $R_{F}^{i}$ and $\tau_{i}$ give valid results, we first determined the "expected" values of these quantities for a given set of conditions (e.g., $\left[\mathrm{Br}^{-}\right]$and $\mathrm{pH}$ ) using output from the model run under these conditions. Expected values for steady-state concentrations of $\mathrm{Br}^{\bullet}, \mathrm{Br}_{2}$, and $\mathrm{HOBr}$ were obtained directly from model runs performed under the same conditions as the corresponding experiment except that AA concentrations were set to zero. (As described in Sect. 2.3, values derived from the competition kinetics analyses are for the case where no allyl alcohol is present.)

For each set of model conditions we also calculated the expected values for the rates of formation of $\mathrm{Br}^{*}(\mathrm{aq})$. For $\mathrm{Br}^{\bullet}$, its primary source $(\sim 100 \%)$ is the reaction of ${ }^{\bullet} \mathrm{OH}$ with $\mathrm{Br}^{-}$(Reaction 29, Table S2), and thus the expected rate of formation $\left(R_{F}^{\mathrm{Br}}\right)$ in the absence of $\mathrm{AA}$ is:

$R_{F}^{\mathrm{Br}}=k_{\mathrm{OH}}^{\mathrm{Br}-}\left[{ }^{\bullet} \mathrm{OH}\right]\left[\mathrm{Br}^{-}\right] Y_{\mathrm{OH}}^{\mathrm{Br}}$

where $k_{\mathrm{OH}}^{B r-}$ is the rate constant for the reaction of $\bullet \mathrm{OH}$ with $\mathrm{Br}^{-}$and $Y_{\mathrm{OH}}^{B r}$ is the yield of $\mathrm{Br}^{\bullet}$ formed from the reaction of - $\mathrm{OH}$ with $\mathrm{Br}^{-}$(Sect. S.5). Since molecular bromine $\left(\mathrm{Br}_{2}\right)$ in our experiments originates primarily from the reaction of ${ }^{\bullet} \mathrm{Br}_{2}^{-}$with hydroperoxyl radical $\left(\mathrm{HO}_{2}^{\bullet}\right)$ (Reaction 45 , Table $\mathrm{S} 2)$, the rate of $\mathrm{Br}_{2}$ formation $\left(R_{F}^{\mathrm{Br}_{2}}\right)$ is calculated from:

$R_{F}^{\mathrm{Br}_{2}}=k_{\mathrm{Br}_{2}^{-}}^{\mathrm{HO}_{2}}\left[\mathrm{HO}_{2}^{\bullet}\right]\left[{ }^{\bullet} \mathrm{Br}_{2}^{-}\right]$

In the case of $\mathrm{HOBr}$, we use the fact that it is at steady-state (as are the other $\mathrm{Br}^{*}(\mathrm{aq})$ ) and thus $R_{F}^{\mathrm{HOBr}}$ is equal to the rate of $\mathrm{HOBr}$ destruction $\left(R_{D}^{\mathrm{HOBr}}\right)$, which can be more accurately 
Table 2. Results of the kinetic analyses of the model and experimental data from the bromide competition kinetics experiments.

\begin{tabular}{|c|c|c|c|c|c|c|c|c|c|c|c|c|}
\hline \multirow{3}{*}{ Species $i$} & \multirow{2}{*}{\multicolumn{2}{|c|}{ Expected values $^{\mathrm{a}}$}} & \multirow{3}{*}{ D.T. ${ }^{\text {b }}$} & \multirow{3}{*}{$\begin{array}{l}\text { Fraction of 3BPD } \\
\text { from listed } \\
\mathrm{Br}^{*} \text { species, } \\
F_{i}^{3 \mathrm{BPD}}(1 \mathrm{RSD})^{\mathrm{c}}\end{array}$} & \multicolumn{4}{|c|}{ Model values with data treatment (MVDT) ${ }^{\mathrm{d}}$} & \multicolumn{4}{|c|}{ Experimental values with data treatment $(\text { EVDT })^{\mathrm{e}}$} \\
\hline & & & & & \multicolumn{2}{|c|}{ Rate of formation, $R_{F}^{i}$} & \multicolumn{2}{|c|}{ Concentration, $[i]$} & \multicolumn{2}{|c|}{ Rate of formation, $R_{F}^{i}$} & \multicolumn{2}{|c|}{ Concentration, $[i]$} \\
\hline & $R_{F}^{i}\left(\mathrm{M} \mathrm{s}^{-1}\right)$ & {$[i](\mathrm{M})$} & & & Value $\left(\mathrm{M} \mathrm{s}^{-1}\right)$ & $\left\{\frac{\text { MVDT }}{\operatorname{Exp}}\right\}$ & Value (M) & $\left\{\frac{\text { MVDT }}{\operatorname{Exp}}\right\}$ & Value $\left(\mathrm{M} \mathrm{s}^{-1}\right)$ & $\left\{\frac{\text { EVDT }}{\text { Exp }}\right\}$ & Value (M) & $\left\{\frac{\text { EVDT }}{\operatorname{Exp}}\right\}$ \\
\hline \multicolumn{13}{|c|}{ Experiment \#1 ( $\left.\left[\mathrm{Br}^{-}\right]=0.80 \mathrm{mM}, \mathrm{pH}=5.3\right)$} \\
\hline \multirow[t]{3}{*}{$\mathrm{Br}^{\bullet}$} & $7.0 \times 10^{-9}$ & $1.9 \times 10^{-15}$ & A & $0.85( \pm 0.1)$ & $6.6 \times 10^{-9}$ & $\{0.95\}$ & $2.1 \times 10^{-15}$ & $\{1.1\}$ & $(3.0 \pm 0.5) \times 10^{-9}$ & $\{0.43\}$ & $(1.7 \pm 0.1) \times 10^{-15}$ & $\{0.90\}$ \\
\hline & & & $\mathrm{B}$ & $0.80( \pm 0.06)$ & $6.9 \times 10^{-10}$ & $\{0.10\}$ & $2.0 \times 10^{-15}$ & $\{1.0\}$ & $(1.2 \pm 0.7) \times 10^{-9}$ & $\{0.18\}$ & $(1.6 \pm 0.1) \times 10^{-15}$ & $\{0.85\}$ \\
\hline & & & $\mathrm{C}$ & 1.0 & $6.5 \times 10^{-9}$ & $\{0.94\}$ & $1.9 \times 10^{-15}$ & $\{0.99\}$ & $(1.5 \pm 1.6) \times 10^{-8}$ & $\{2.1\}$ & $(1.6 \pm 0.1) \times 10^{-15}$ & $\{0.83\}$ \\
\hline \multirow[t]{2}{*}{$\mathrm{Br}_{2}$} & $5.1 \times 10^{-11}$ & $4.6 \times 10^{-13}$ & B & $0.13( \pm 0.03)$ & $2.0 \times 10^{-11}$ & $\{0.39\}$ & $3.3 \times 10^{-13}$ & $\{0.71\}$ & $(3.5 \pm 2.2) \times 10^{-11}$ & $\{0.68\}$ & $(2.8 \pm 0.1) \times 10^{-13}$ & $\{0.60\}$ \\
\hline & & & $\mathrm{C}$ & 1.0 & $3.2 \times 10^{-11}$ & $\{0.63\}$ & $4.6 \times 10^{-13}$ & $\{0.99\}$ & $(4.3 \pm 1.3) \times 10^{-11}$ & $\{0.83\}$ & $(3.8 \pm 0.2) \times 10^{-13}$ & $\{0.82\}$ \\
\hline \multirow[t]{2}{*}{$\mathrm{HOBr}$} & $1.6 \times 10^{-11}$ & $3.1 \times 10^{-13}$ & $\mathrm{~B}$ & $0.08( \pm 0.03)$ & $1.2 \times 10^{-11}$ & $\{0.72\}$ & $2.0 \times 10^{-13}$ & $\{0.63\}$ & $(2.1 \pm 1.3) \times 10^{-11}$ & $\{1.3\}$ & $(1.6 \pm 0.1) \times 10^{-13}$ & $\{0.53\}$ \\
\hline & & & $\mathrm{C}$ & 1.0 & $1.3 \times 10^{-11}$ & $\{0.78\}$ & $3.1 \times 10^{-13}$ & $\{1.0\}$ & $(1.5 \pm 0.4) \times 10^{-11}$ & $\{0.91\}$ & $(2.6 \pm 0.2) \times 10^{-13}$ & $\{0.84\}$ \\
\hline \multicolumn{13}{|c|}{ Experiment $\# 2\left(\left[\mathrm{Br}^{-}\right]=0.80 \mathrm{mM}, \mathrm{pH}=3.0\right)$} \\
\hline \multirow[t]{3}{*}{$\mathrm{Br}^{\bullet}$} & $7.5 \times 10^{-9}$ & $1.9 \times 10^{-15}$ & A & $0.56( \pm 0.39)$ & $4.6 \times 10^{-9}$ & $\{0.61\}$ & $3.5 \times 10^{-14}$ & $\{19\}$ & $(1.9 \pm 0.1) \times 10^{-9}$ & $\{0.26\}$ & $(2.2 \pm 10) \times 10^{-13}$ & $\{118\}$ \\
\hline & & & B & $0.12( \pm 0.07)$ & $3.3 \times 10^{-10}$ & $\{0.04\}$ & $7.2 \times 10^{-15}$ & $\{3.8\}$ & $(4.8 \pm 0.6) \times 10^{-10}$ & $\{0.07\}$ & $(9.6 \pm 2.5) \times 10^{-15}$ & $\{5.1\}$ \\
\hline & & & $\mathrm{C}$ & 1.0 & $8.1 \times 10^{-9}$ & $\{1.1\}$ & $1.7 \times 10^{-15}$ & $\{0.92\}$ & $(1.9 \pm 3.0) \times 10^{-8}$ & $\{2.6\}$ & $(2.5 \pm 0.1) \times 10^{-15}$ & $\{1.4\}$ \\
\hline \multirow[t]{2}{*}{$\mathrm{Br}_{2}$} & $5.4 \times 10^{-10}$ & $6.2 \times 10^{-11}$ & B & $0.88( \pm 0.07)$ & $4.4 \times 10^{-10}$ & $\{0.80\}$ & $5.6 \times 10^{-11}$ & $\{0.89\}$ & $(6.4 \pm 1.5) \times 10^{-10}$ & $\{1.2\}$ & $(7.4 \pm 1.9) \times 10^{-11}$ & $\{1.2\}$ \\
\hline & & & $\mathrm{C}$ & 1.0 & $4.9 \times 10^{-10}$ & $\{0.89\}$ & $6.0 \times 10^{-11}$ & $\{0.96\}$ & $(7.4 \pm 0.8) \times 10^{-10}$ & $\{1.4\}$ & $(8.0 \pm 2.8) \times 10^{-11}$ & $\{1.3\}$ \\
\hline \multicolumn{13}{|c|}{ Experiment $\# 3\left(\left[\mathrm{Br}^{-}\right]=0.40 \mathrm{mM}, \mathrm{pH}=5.4\right)$} \\
\hline \multirow[t]{3}{*}{$\mathrm{Br}^{\bullet}$} & $7.4 \times 10^{-9}$ & $1.9 \times 10^{-15}$ & A & $0.93( \pm 0.06)$ & $7.2 \times 10^{-9}$ & $\{0.98\}$ & $1.7 \times 10^{-15}$ & $\{0.91\}$ & $(2.3 \pm 0.2) \times 10^{-9}$ & $\{0.31\}$ & $(1.7 \pm 0.1) \times 10^{-15}$ & $\{0.88\}$ \\
\hline & & & B & $0.90( \pm 0.03)$ & $4.5 \times 10^{-10}$ & $\{0.06\}$ & $1.7 \times 10^{-15}$ & $\{0.89\}$ & $(3.0 \pm 0.7) \times 10^{-10}$ & $\{0.04\}$ & $(1.6 \pm 0.1) \times 10^{-15}$ & $\{0.85\}$ \\
\hline & & & $\mathrm{C}$ & 1.0 & $7.1 \times 10^{-9}$ & $\{0.96\}$ & $1.9 \times 10^{-15}$ & $\{0.99\}$ & $(4.6 \pm 1.2) \times 10^{-9}$ & $\{0.62\}$ & $(2.9 \pm 0.2) \times 10^{-15}$ & $\{1.5\}$ \\
\hline \multirow[t]{2}{*}{$\mathrm{Br}_{2}$} & $2.5 \times 10^{-11}$ & $1.9 \times 10^{-13}$ & $\mathrm{~B}$ & $0.06( \pm 0.02)$ & $5.5 \times 10^{-12}$ & $\{0.22\}$ & $1.2 \times 10^{-13}$ & $\{0.66\}$ & $(3.7 \pm 0.9) \times 10^{-12}$ & $\{0.15\}$ & $(1.2 \pm 0.1) \times 10^{-13}$ & $\{0.63\}$ \\
\hline & & & $\mathrm{C}$ & 1.0 & $1.6 \times 10^{-11}$ & $\{0.64\}$ & $1.8 \times 10^{-13}$ & $\{0.99\}$ & $(8.2 \pm 0.6) \times 10^{-12}$ & $\{0.33\}$ & $(2.2 \pm 0.3) \times 10^{-13}$ & $\{1.2\}$ \\
\hline \multirow[t]{2}{*}{$\mathrm{HOBr}$} & $9.3 \times 10^{-12}$ & $1.6 \times 10^{-13}$ & B & $0.05( \pm 0.02)$ & $4.1 \times 10^{-12}$ & $\{0.45\}$ & $9.0 \times 10^{-14}$ & $\{0.56\}$ & $(2.8 \pm 0.6) \times 10^{-12}$ & $\{0.30\}$ & $(8.7 \pm 0.5) \times 10^{-14}$ & $\{0.54\}$ \\
\hline & & & $\mathrm{C}$ & 1.0 & $6.4 \times 10^{-12}$ & $\{0.69\}$ & $1.7 \times 10^{-13}$ & $\{1.0\}$ & $(3.6 \pm 0.2) \times 10^{-12}$ & $\{0.39\}$ & $(2.0 \pm 0.2) \times 10^{-13}$ & $\{1.3\}$ \\
\hline \multicolumn{13}{|c|}{ Experiment \#4 ( [ $\left.\left.\mathrm{Br}^{-}\right]=0.80 \mathrm{mM}, \mathrm{pH}=8.4\right)$} \\
\hline \multirow[t]{3}{*}{$\mathrm{Br}^{\bullet}$} & $5.8 \times 10^{-9}$ & $1.3 \times 10^{-15}$ & A & $0.99( \pm 0.01)$ & $5.7 \times 10^{-9}$ & $\{0.97\}$ & $1.3 \times 10^{-15}$ & $\{0.94\}$ & $(3.1 \pm 0.1) \times 10^{-9}$ & $\{0.52\}$ & $(2.2 \pm 0.1) \times 10^{-15}$ & $\{1.7\}$ \\
\hline & & & $\mathrm{B}$ & $0.99( \pm 0.01)$ & $6.7 \times 10^{-10}$ & $\{0.12\}$ & $1.3 \times 10^{-15}$ & $\{0.94\}$ & $(3.0 \pm 0.3) \times 10^{-10}$ & $\{0.05\}$ & $(2.2 \pm 0.1) \times 10^{-15}$ & $\{1.7\}$ \\
\hline & & & $\mathrm{C}$ & 1 & $5.5 \times 10^{-9}$ & $\{0.94\}$ & $1.4 \times 10^{-15}$ & $\{1.0\}$ & $(2.4 \pm 0.3) \times 10^{-9}$ & $\{0.41\}$ & $(2.5 \pm 0.1) \times 10^{-15}$ & $\{1.8\}$ \\
\hline \multicolumn{13}{|c|}{ Experiment $\# 5\left(\left[\mathrm{Br}^{-}\right]=8.0 \mathrm{mM}, \mathrm{pH}=5.3\right)$} \\
\hline \multirow[t]{2}{*}{$\mathrm{Br}^{\bullet}$} & $5.5 \times 10^{-9}$ & $1.4 \times 10^{-15}$ & $\mathrm{~B}$ & $0.39( \pm 0.07)$ & $9.4 \times 10^{-10}$ & $\{0.17\}$ & $2.6 \times 10^{-15}$ & $\{1.8\}$ & $(7.7 \pm 1.7) \times 10^{-10}$ & $\{0.14\}$ & $(3.7 \pm 0.2) \times 10^{-15}$ & $\{2.6\}$ \\
\hline & & & $\mathrm{C}$ & 1.0 & $5.3 \times 10^{-9}$ & $\{0.96\}$ & $1.4 \times 10^{-15}$ & $\{0.96\}$ & $(3.5 \pm 0.5) \times 10^{-9}$ & $\{0.64\}$ & $(1.6 \pm 0.1) \times 10^{-15}$ & $\{1.1\}$ \\
\hline $\mathrm{Br}_{2}$ & $3.2 \times 10^{-10}$ & $5.0 \times 10^{-12}$ & B & $0.55( \pm 0.06)$ & $2.4 \times 10^{-10}$ & $\{0.74\}$ & $3.8 \times 10^{-12}$ & $\{0.76\}$ & $(1.9 \pm 0.4) \times 10^{-10}$ & $\{0.61\}$ & $(5.4 \pm 0.3) \times 10^{-12}$ & $\{1.1\}$ \\
\hline & & & $\mathrm{C}$ & 1.0 & $2.0 \times 10^{-10}$ & $\{0.63\}$ & $6.0 \times 10^{-12}$ & $\{1.2\}$ & $(1.7 \pm 0.2) \times 10^{-10}$ & $\{0.53\}$ & $(1.6 \pm 0.1) \times 10^{-11}$ & $\{3.2\}$ \\
\hline $\mathrm{HOBr}$ & $3.2 \times 10^{-11}$ & $5.8 \times 10^{-13}$ & B & $0.06( \pm 0.01)$ & $2.6 \times 10^{-11}$ & $\{0.80\}$ & $4.1 \times 10^{-13}$ & $\{0.70\}$ & $(2.1 \pm 0.5) \times 10^{-11}$ & $\{0.66\}$ & $(5.9 \pm 0.3) \times 10^{-13}$ & $\{1.0\}$ \\
\hline & & & $\mathrm{C}$ & 1 & $1.9 \times 10^{-11}$ & $\{0.60\}$ & $8.4 \times 10^{-13}$ & $\{1.4\}$ & $(1.6 \pm 0.2) \times 10^{-11}$ & $\{0.51\}$ & $(1.2 \pm 0.1) \times 10^{-12}$ & $\{2.1\}$ \\
\hline
\end{tabular}

Lifetimes $\left(\tau_{i}\right)$ are not included in the table but can be calculated as $\tau_{i}=[i] / R_{F}^{i}$. Similarly, values of MVDT/Exp for $\tau_{i}$ are calculated by dividing the value of MVDT/Exp for [i] by the MVDT/Exp value for $R_{F}^{i}$. Values for EVDT/Exp for $\tau_{i}$ are calculated in an analogous manner.

${ }^{a}$ Expected values are model-derived best estimates of the actual values for $[i]$ and $R_{F}^{i}$ in the experimental solutions in the absence of AA (Sect. 3.5).

${ }^{\mathrm{b}}$ Data treatments (D.T.) are discussed in Sects. 3.6 and 3.7. Data treatment A, which works only for $\mathrm{Br}^{\bullet}$, uses all data in the inverse plot and accounts for the AA effect. Data treatments $\mathrm{B}$ and $\mathrm{C}$ use data in the linear range of the inverse plot with either a rough correction for the $F_{i}^{3 \mathrm{BPD}}$ effect (treatment B) or corrections for both the AA and $F_{i}^{3 \mathrm{BPD}}$ effects (treatment C).

${ }^{c}$ Average ( \pm 1 relative standard deviation) of $F_{i}^{3 \mathrm{BPD}}$ calculated over either the linear [AA] range (Table 1$)$ for treatments $\mathrm{B}$ and $\mathrm{C}$, or the entire [AA] range for treatment A. Values for data treatment $\mathrm{C}$ are listed as 1.0 since in this case a separate inverse plot is made for each individual $\mathrm{Br}^{*}$ species.

${ }^{\mathrm{d}}$ Calculated by taking the model-derived results through the data treatment steps (Sect. 3.6).

${ }^{\mathrm{e}}$ Calculated by taking the experimental results through the data treatment steps (Sect. 3.7). Errors are \pm 1 standard error calculated based on the standard errors of the slope and y-intercept from the inverse plots.

calculated. Since $\mathrm{H}_{2} \mathrm{O}_{2}$ accounts for $>99 \%$ of $\mathrm{HOBr}$ loss in our experiments

$R_{F}^{\mathrm{HOBr}}=R_{D}^{\mathrm{HOBr}}=k_{\mathrm{HOBr}}^{\mathrm{H}_{2} \mathrm{O}_{2}}\left[\mathrm{H}_{2} \mathrm{O}_{2}\right][\mathrm{HOBr}]$

Values of $\left[{ }^{\bullet} \mathrm{OH}\right],\left[\mathrm{HO}_{2}^{\bullet}\right],\left[{ }^{\bullet} \mathrm{Br}_{2}^{-}\right],\left[\mathrm{H}_{2} \mathrm{O}_{2}\right]$, and $[\mathrm{HOBr}]$ in Eqs. (2-4) are taken directly from the model. Expected values for [i] and $R_{F}^{i}$ under our range of experimental conditions are shown in Table 2. Expected values for $\tau_{i}$ are not included in Table 2, but can be calculated as $[i] / R_{F}^{i}$.
3.6 Competition kinetics: model experiments and data treatments

As described above, the goal in this first step of technique testing is to examine the accuracy of the derived equations (and their accompanying assumptions) for determining [i], $R_{F}^{i}$, and $\tau_{i}$. To do this we use "data" generated from models run using the conditions of the competition kinetic experiments (e.g., pH, $\mathrm{Br}^{-}$and [AA]; Table 1). The output from these "model experiments" $\left(R_{F \text {, tot }}^{3 \mathrm{BPD}}\right.$ as a function of $\left.[\mathrm{AA}]\right)$ is 
then used to generate inverse plots and calculate values of $[i]$, $R_{F}^{i}$, and $\tau_{i}$ using one of three different data treatments (A, B, and $\mathrm{C}$ ). The resulting values (referred to as "model values obtained with data treatments" or MVDT) are then compared to the expected values obtained from the model (Sect. 3.5).

\subsubsection{Data treatment A}

In the first data treatment we fit a curve to the entire set of inverse plot data $\left(1 / R_{F, \text { tot }}^{3 \mathrm{BPD}}\right.$ vs. $\left.1 /[\mathrm{AA}]\right)$ using Eq. (S13) in order to obtain values for $\mathrm{a}, \mathrm{b}$, and c. Values of $[i], R_{F}^{i}$, and $\tau_{i}$ are then calculated using Eqs. (S17-S19). Although this technique can only be used for $\mathrm{Br}^{\bullet}$ (Sect. 2.3), its advantage is that Eq. (S13) takes into account the effects that AA has on $\left[{ }^{\bullet} \mathrm{OH}\right]$ and, therefore, on $R_{F}^{i}$ and $R_{F \text {, tot }}^{3 \mathrm{BPD}}$. Data treatment A was evaluated for Experiments 1-4 by using the $\mathrm{Br}^{-}$Full Model with the experimental conditions listed in Table 1. It could not be applied to Experiment 5 because the inverse plot is linear over the entire AA range, precluding us from determining an accurate value for $c$. As with subsequent treatments, the validity of treatment A was evaluated by examining the ratio of the model value to the expected value; these ratios (MVDT/Exp) are shown in Table 2.

Based on these results, data treatment A gives MVDT values for $\left[\mathrm{Br}^{\bullet}\right]$ and $R_{F}^{\mathrm{Br}}$ that are within $10 \%$ of expected values when $\mathrm{Br}^{\bullet}$ is the dominant source of 3BPD at all AA concentrations (e.g., in Experiments 1, 3, and 4, where the average value for $F_{\mathrm{Br}}^{3 \mathrm{BPD}}$ in a given experiment is $\geq 0.85$ ). It is important to note that $F_{\mathrm{Br}}^{3 \mathrm{BPD}}$ used in these calculations is the average value over the entire 1/[AA] range, calculated based on data obtained from the $\mathrm{Br}^{-}$Full Model. The small deviations between the MVDT and expected values are apparently a result of the error associated with this averaging. In cases where $F_{\mathrm{Br}}^{3 \mathrm{BPD}}$ is not large throughout the range of [AA], data treatment A does not perform well. For example, in Experiment $2\left(\mathrm{pH} 3.0, F_{\mathrm{Br}}^{3 \mathrm{BPD}}( \pm 1 \mathrm{RSD})=0.56 \pm 0.39\right)$ the MVDT value for $R_{F}^{\mathrm{Br}}$ is within a factor of 2 of the expected value, but $\left[\mathrm{Br}^{\bullet}\right]$ is overestimated by 19 times (Table 2 ) and $\tau_{\mathrm{Br}}$ is too large by $\sim 30$ times (not shown).

\subsubsection{Data treatment B}

The second data treatment involves fitting a line to the linear portion of the inverse plot using Eq. (S25) with a value of $F_{i}^{3 \mathrm{BPD}}$ from the $\mathrm{Br}^{-}$Full Model, where $F_{i}^{3 \mathrm{BPD}}$ here is the fraction of 3BPD from $i$ averaged throughout the linear range of the inverse plot. The slope and y-intercept from the linear regression to the inverse plot data $\left(1 / R_{F \text {, tot }}^{3 \mathrm{BPD}}\right.$ versus 1/[AA]) are then used in Eqs. (S28-S30) to calculate $[i]$, $R_{F}^{i}$, and $\tau_{i}$. As seen in Table 2, with one exception $\left(\mathrm{Br}^{\bullet}\right.$ in Experiment 2), this simple analysis generates MVDT values of $[i]$ for all species that are within a factor of 2 of the expected values. This is true even for species that are only minor sources of 3BPD (e.g., HOBr in Experiments 1, 3, and 5 where $F_{\mathrm{HOBr}}^{3 \mathrm{BPD}} \leq 0.08$ ). In addition, MVDT values of $R_{F}^{i}$ obtained for $\mathrm{Br}_{2}$ and $\mathrm{HOBr}$ using treatment $\mathrm{B}$ are nearly all within a factor of 3 of the expected values. However, for reasons that are unclear, values of $R_{F}^{i}$ for $\mathrm{Br}^{\bullet}$ are underestimated by factors of 6 to 25 times using treatment B (Table 2). Errors in $\tau_{i}$ vary significantly and reflect the combination of errors associated with $R_{F}^{i}$ and [i].

\subsubsection{Data treatment C}

Like treatment B, treatment C is based on applying Eq. (S25) to the linear portion of the inverse plot. However, in treatment $\mathrm{C}$ more effort is taken to correct the data for the two possible biases associated with the competition kinetics derivations. The first bias is the "AA effect", where the presence of AA reduces the formation rates of $\mathrm{Br} *(\mathrm{aq})$ and 3BPD. This bias appears because the kinetic equations for the linear portion of the inverse plot (e.g., Eq. S25) assume that the presence of low AA concentrations does not significantly affect $R_{F}^{i}$ or $R_{F \text {, tot }}^{3 \mathrm{BPD}}$ (Sect. 2.3). The second bias, the " $F_{i}^{3 \mathrm{BPD}}$ effect", arises from the fact that three species $\left(i=\mathrm{Br}{ }^{\bullet}\right.$, $\mathrm{Br}_{2}$, and $\mathrm{HOBr}$ ) are responsible for different fractions of the 3BPD formed (i.e., $F_{i}^{3 \mathrm{BPD}}$, Sect. S.4) and these contributions can vary with $[\mathrm{AA}]$.

To correct for these possible biases in the model "data" using data treatment $\mathrm{C}$, we first run a model that is identical to the $\mathrm{Br}^{-}$Full Model except that ${ }^{\bullet} \mathrm{OH}$ is not allowed to react with AA. This "No ${ }^{\bullet} \mathrm{OH}+\mathrm{AA}$ Model" is run under the desired experimental conditions (e.g., Table 1) and at each AA concentration used in the model $R_{F \text {, tot }}^{3 \mathrm{BPD}}$ is recorded and the value of $F_{i}^{3 \mathrm{BPD}}$ is determined (Eq. S31). From these data we calculate $R_{F, i}^{3 \mathrm{BPD}}$, the rate of 3BPD formation from an individual reactive bromine species $i\left(i=\mathrm{Br}^{\bullet}, \mathrm{Br}_{2}\right.$, and $\left.\mathrm{HOBr}\right)$ at each [AA]:

$R_{F, i}^{3 \mathrm{BPD}}=R_{F, \text { tot }}^{3 \mathrm{BPD}} \times F_{i}^{3 \mathrm{BPD}}$

The next step is to use these data to generate inverse plots for each species (i.e., $1 / R_{F, i}^{3 \mathrm{BPD}}$ as a function of $1 /[\mathrm{AA}]$ ). The resulting inverse plots have been corrected for both the $F_{i}^{3 \mathrm{BPD}}$ and AA effects. The slope and y-intercept from the inverse plots are then used in Eqs. (S28) and (S29) to evaluate data treatment $\mathrm{C}$. In contrast to treatments $\mathrm{A}$ and $\mathrm{B}, F_{i}^{3 \mathrm{BPD}}$ for treatment $\mathrm{C}$ is set to 1 for each species because each inverse plot represents 3BPD formation from only one $\mathrm{Br}^{*}(\mathrm{aq})$ species. This correction for $F_{i}^{3 \mathrm{BPD}}$ in treatment $\mathrm{C}$ is more accurate than that used in treatments $\mathrm{A}$ and $\mathrm{B}$ since it accounts for the fact that $F_{i}^{3 \mathrm{BPD}}$ can vary with [AA].

As seen in Table 2, MVDT values obtained through treatment $\mathrm{C}$ agree very well with the expected values for $[i]$ and $R_{F}^{i}$. The $[i]$ values obtained for all three species from this treatment are typically within $10 \%$, and always within $40 \%$, of the expected values while values of $R_{F}^{i}$ are within 10-40\% of the expected values. Furthermore, those species with the largest discrepancies in $R_{F}^{i}$ account for only a small fraction, typically $<10 \%$, of the 3BPD formed (e.g., $\mathrm{Br}_{2}$ in experiment 3 where $F_{B r 2}^{3 \mathrm{BPD}}=0.06$ ). Values for $\tau_{i}$ are also generally 
quite good: typically within $15 \%$ of the expected value and always within a factor of 2.4 .

\subsubsection{Summary of data treatments with model-derived "data"}

Overall, data treatment A, which can only be used to determine $\mathrm{Br}^{\bullet}$ kinetics (Sect. 2.3), works very well for determining values of $\left[\mathrm{Br}{ }^{\bullet}\right], R_{F}^{\mathrm{Br}}$, and $\tau_{\mathrm{Br}}$ under conditions where $\mathrm{Br}{ }^{\bullet}$ is the dominant source of 3BPD at all [AA] values used in the experiment (Table 1). With one exception ( $\left[\mathrm{Br}_{2}\right]$ in experiment 3), treatment $\mathrm{B}$ provides good values (within a factor of $\approx 2$ of expected values) of [i] and $R_{F}^{i}$ for $\mathrm{Br}_{2}$ and $\mathrm{HOBr}$ under our experimental conditions. This treatment also provides excellent results for $\left[\mathrm{Br}^{\bullet}\right]$ when $\mathrm{Br}^{\bullet}$ is the dominant source of 3BPD, but always significantly underpredicts $R_{F}^{\mathrm{Br}}$ (Table 2) and does not consistently give reliable results for $\tau_{i}$ for any $\mathrm{Br}^{*}(\mathrm{aq})$. The more complicated treatment $\mathrm{C}$ consistently provides the best results for all species under all conditions: i) values of $[i]$ are within $10 \%$ of expected values except in two cases (within $20-40 \%$ for $\mathrm{Br}_{2}$ and $\mathrm{HOBr}$ in Experiment 5), ii) rates of formation $\left(R_{F}^{i}\right)$ are within $10 \%$ of expected values for $\mathrm{Br}^{\bullet}$, and within $11-40 \%$ for $\mathrm{Br}_{2}$ and $\mathrm{HOBr}$, and iii) lifetimes $\left(\tau_{i}\right)$ are within $15 \%$ of expected values for $\mathrm{Br}^{\bullet}$ and within a factor of 1.1-2.4 for $\mathrm{Br}_{2}$ and $\mathrm{HOBr}$.

3.7 Competition kinetics: experimental data and determination of $[i], R_{F}^{i}$, and $\tau_{i}$

\subsubsection{Overview and procedures}

Based on the model-derived results above, the kinetic equations we derived to determine $[i], R_{F}^{i}$, and $\tau_{i}$ are generally valid, although in some cases corrections are needed to account for the $\mathrm{AA}$ and $F_{i}^{3 \mathrm{BPD}}$ effects. In this section we perform the second testing step: evaluating the probe technique using experimental data. To do this we analyze the data from the laboratory experiments using the three different data treatments in order to determine the kinetics of $\mathrm{Br}^{*}(\mathrm{aq})$ under different experimental conditions. The values obtained from this treatment of the experimental data are referred to as EVDT values (experimental values with data treatment). We then compare these EVDT values with the model-derived expected values (Sect. 3.5) to determine the reliability of the probe technique.

For data treatments $\mathrm{A}$ and $\mathrm{B}$, values of $[i], R_{F}^{i}$, and $\tau_{i}$ from the experimental data are calculated as described for the model data (Sects. 3.6.1 and 3.6.2), but for data treatment $\mathrm{C}$ the steps are slightly different in order to correct for both the $F_{i}^{3 \mathrm{BPD}}$ and AA effects. In the first step we separately run the $\mathrm{Br}^{-}$Full Model and the $\mathrm{No}^{\bullet} \mathrm{OH}+\mathrm{AA}$ Model (Sect. 3.6.3) with the desired experimental conditions (Table 1). For both models, $R_{F \text {, tot }}^{3 \mathrm{BPD}}$ is recorded and $F_{i}^{3 \mathrm{BPD}}$ is calculated for each [AA]. We then calculate $R_{F, i}^{3 \mathrm{BPD}}$ (Eq. 5) for each species $i$ at every [AA] for both models and use the data to generate in- verse plots for each species. The $R_{F, i}^{3 \mathrm{BPD}}$ inverse plots from the $\mathrm{Br}^{-}$Full Model have been corrected for the $F_{i}^{3 \mathrm{BPD}}$ effect, while those from the No ${ }^{\bullet} \mathrm{OH}+\mathrm{AA}$ Model have been corrected for both the $F_{i}^{3 \mathrm{BPD}}$ and AA effects. Thus differences in the corresponding slopes (and y-intercepts) between the two sets of model data should be due to the AA effect. In the next step of treatment $\mathrm{C}$ we use these differences to calculate correction factors for the slope $\left(b^{\prime}\right)$ and y-intercept $\left(a^{\prime}\right)$ for each $i\left(C_{i}^{b^{\prime}}\right.$ and $C_{i}^{a^{\prime}}$, respectively):

$C_{i}^{b^{\prime}}=\frac{b_{i}^{\prime}(\mathrm{No} \mathrm{OH}+\mathrm{AA} \text { Model })}{b^{\prime}{ }_{i}\left(\mathrm{Br}^{-} \text {Full Model }\right)}$

$C_{i}^{a^{\prime}}=\frac{a_{i}^{\prime}(\mathrm{No} \mathrm{OH}+\mathrm{AA} \text { Model })}{a_{i}^{\prime}\left(\mathrm{Br}^{-} \text {Full Model }\right)}$

where $b_{i}^{\prime}$ and $a_{i}^{\prime}$ are the slope and y-intercept, respectively, from the linear regression to the inverse plot for each species generated from the specified model data (" $\mathrm{Br}^{-}$Full" or "No •OH+AA"). Equations (S28-S30) can now be rewritten as follows:

$$
\begin{aligned}
{[i] } & =\frac{1}{b_{i}^{\prime} Y_{i}^{3 \mathrm{BPD}} k_{i}^{\mathrm{AA}} C_{i}^{b^{\prime}}} \\
R_{F}^{i} & =\frac{1}{a_{i}^{\prime} Y_{i}^{3 \mathrm{BPD}} C_{i}^{a^{\prime}}} \\
\tau_{i} & =\frac{a_{i}^{\prime} C_{i}^{a^{\prime}}}{b_{i}^{\prime} k_{i}^{\mathrm{AA}} C_{i}^{b^{\prime}}}=\frac{[i]}{R_{F}^{i}}
\end{aligned}
$$

The values of [i], $R_{F}^{i}$, and $\tau_{i}$ obtained with these equations have been corrected for both the $F_{i}^{3 \mathrm{BPD}}$ and AA effects.

\subsubsection{Kinetic results from experiments $1-5$}

The $R_{F \text {, tot }}^{3 \mathrm{BPD}}$ data from Fig. 5a were used to generate the inverse plot for Experiment $1\left(0.80 \mathrm{mM} \mathrm{Br}^{-}, \mathrm{pH} 5.3\right)$ shown in Fig. 6a. In the linear portion of this plot ([AA] $<150 \mu \mathrm{M}$ or $\left.1 /[\mathrm{AA}]>6.7 \times 10^{3} \mathrm{M}^{-1}\right), \mathrm{Br}^{-}$is the dominant sink for ${ }^{\bullet} \mathrm{OH}$, representing $95-55 \%$ of the total sink. In the non-linear portion $\left([\mathrm{AA}]>300 \mu \mathrm{M}\right.$ or $1 /[\mathrm{AA}]<3.3 \times 10^{3} \mathrm{M}^{-1}$ ), allyl alcohol is the dominant sink for ${ }^{\bullet} \mathrm{OH}$ (accounting for $62-85 \%$ of - OH loss), and the inverse plot curves up due to the scavenging of $\bullet \mathrm{OH}$ by AA (i.e., the AA effect). As mentioned in Sect. 2.3, the steady-state concentrations of $\mathrm{Br}^{\bullet}, \mathrm{Br}_{2}$ and $\mathrm{HOBr}$ change as a function of $[\mathrm{AA}]$ (as well as $\mathrm{pH}$ and $\left[\mathrm{Br}^{-}\right]$) and, therefore, so do their relative contributions as sources of 3BPD. An example of this is shown in Fig. $6 \mathrm{~b}$ for experiment 1 : values of $F_{i}^{3 \mathrm{BPD}}$ change slowly with increasing 1/[AA] but are relatively constant in the linear portion of the inverse plot.

Results from all five of the kinetics experiments are listed in Table 2. Before examining these results, it is important to note that the previously discussed MVDT values for $[i]$, $R_{F}^{i}$, and $\tau_{i}$ represent the upper limits of data treatment performance; i.e., the experimentally derived values (EVDT) 


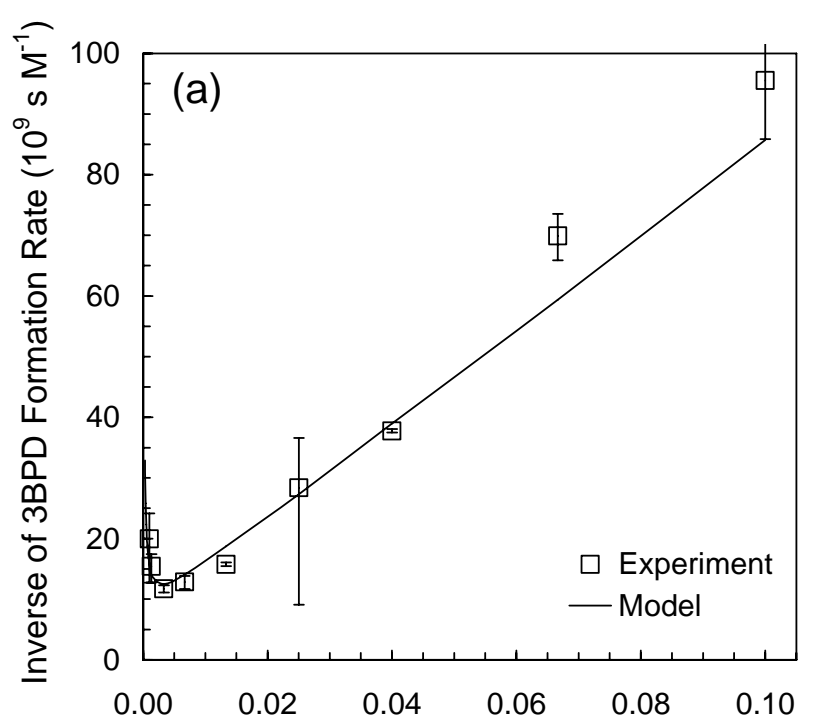

Inverse of Allyl Alcohol Concentration $\left(10^{6} \mathrm{M}^{-1}\right)$

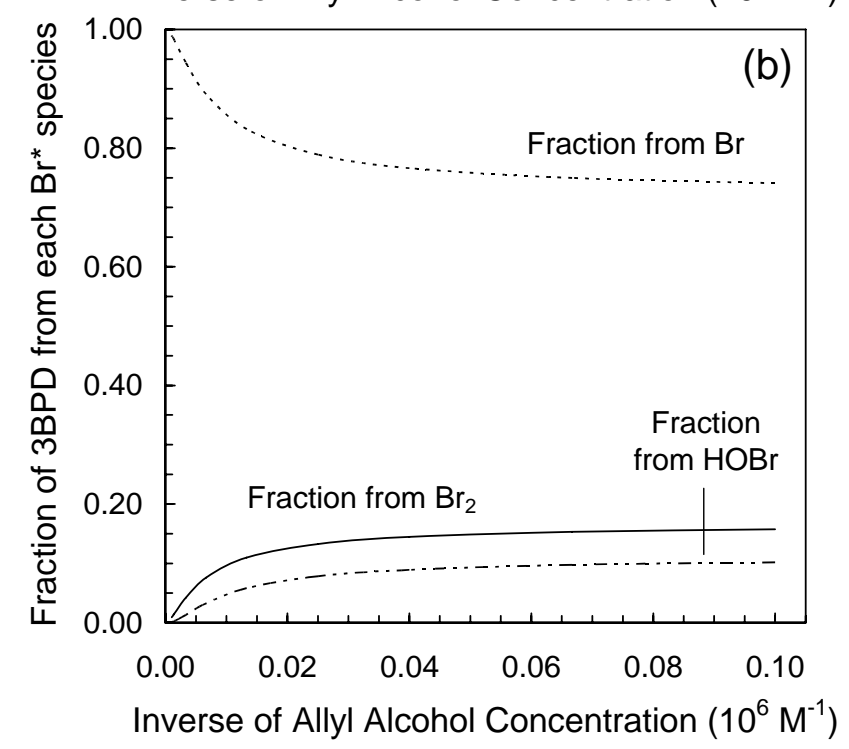

Fig. 6. (a) Inverse plot for the competition kinetics experiment 1 described in Table 1 and Fig. $5 \mathrm{a}\left(\left[\mathrm{Br}^{-}\right]=0.80 \mathrm{mM}, \mathrm{pH}\right.$ 5.3). The squares are the inverse of the experimentally determined rates of 3BPD formation and the line shows the corresponding results from the $\mathrm{Br}^{-}$Full Model. Error bars represent $90 \%$ confidence intervals around the experimental data. (b) The fractions of 3BPD formed from the reaction of species $i$ with AA $\left(F_{i}^{3 \mathrm{BPD}}\right)$ as a function of 1/[AA] for competition kinetics experiment 1 in Fig. 6 a.

for these three parameters should be no closer to the expected values than the MVDT values. Cases where EVDT values are closer to the expected values are most likely a result of random experimental errors. Furthermore, for a given $\mathrm{Br}^{*}(\mathrm{aq})$ species under a given set of conditions, the best data treatment(s) for the experimental data should be the same as that determined from the MVDT values.
Based on the model experiments (Sect. 3.6), treatments A and $\mathrm{C}$ should provide the best results for calculating $\left[\mathrm{Br}^{\bullet}\right]$ and $R_{F}^{\mathrm{Br}}$ from the experimental data. As shown in Table 2, this is nearly always the case. Experimentally derived values of $\left[\mathrm{Br}^{\bullet}\right]$ are within a factor of 2 of expected values for these data treatments (except in Experiment 2 where $F_{\mathrm{Br}}^{3 \mathrm{BPD}}$ is quite variable), while EVDT values for $R_{F}^{\mathrm{Br}}$ are within a factor of 4 . Treatment B usually provides good results for $\left[\mathrm{Br}^{\bullet}\right]$ (except at low $\mathrm{pH}$ where $F_{\mathrm{Br}}^{3 \mathrm{BPD}}$ is variable) but underestimates $R_{F}^{i}$ by a factor of 6-25, consistent with what was observed for the model values. For $\mathrm{Br}_{2}$ and $\mathrm{HOBr}$, treatment $\mathrm{C}$ generally provides EVDT values for $[i]$ and $R_{F}^{i}$ that are better than those from treatment $\mathrm{B}$, consistent with the model evaluations. Overall, when using the best data treatment as determined by the model evaluation, EVDT values of $[i]$ are nearly always within a factor of 2 of the expected values and $R_{F}^{i}$ values are almost all within a factor of 3 . (Note that these discrepancies in $R_{F}^{i}$ are sometimes within the errors of the experimental measurements.) While these numbers represent the overall technique performance, results are generally better for individual experiments where one $\mathrm{Br}^{*}(\mathrm{aq})$ species accounts for the bulk of 3BPD formation at all AA values (e.g., $\mathrm{Br}^{\bullet}$ in experiment 1 ). Conversely, the method generally performs less well for species where $F_{\mathrm{Br}}^{3 \mathrm{BPD}}$ is small or changes significantly over the $[\mathrm{AA}]$ range.

Overall, results from the experimental data demonstrate that under the variety of conditions tested, the AA chemical probe technique is capable of measuring $[i]$ and $R_{F}^{i}$ (as well as $\tau_{i}$ ) with fair to excellent accuracy, depending on the kinetic parameter, species, and data treatment selected. As was the case for the model experiments, the most accurate experimental values typically are obtained for $[i]$ while values for $R_{F}^{i}$ and $\tau_{i}$ are less accurate. Results from the experimental data often do not compare as well with the expected values as do values from the model experiments, but this is expected due to experimental errors and the fact that the experimental data are not perfectly predicted by the model.

In general, the experimental results reflect those of the model experiments, namely that treatment $\mathrm{C}$ gives the best overall results. However, it is important to note that treatment A, which requires no model-based corrections, also provides good results for $\left[\mathrm{Br}^{\bullet}\right], R_{F}^{\mathrm{Br}}$, and, $\tau_{\mathrm{Br}}$ under conditions where $\mathrm{Br}^{\bullet}$ is the dominant species responsible for 3BPD formation across the entire experimental [AA] range. Based on our modeling results, $\mathrm{Br}^{\bullet}$ will dominate $3 \mathrm{BPD}$ formation at higher $\mathrm{pH}$ values, e.g., those typical of seawater $(0.80 \mathrm{mM}$ $\mathrm{Br}^{-}$, pH 8.1; Zafiriou et al., 1987). As shown in experiment 4 (Table 2), the probe technique with treatment A could be used for studies of $\mathrm{Br}^{\bullet}$ kinetics in bromide solutions with seawater conditions of $\left[\mathrm{Br}^{-}\right]$and $\mathrm{pH}$ without any input from the numerical model and still yield values of $\left[\mathrm{Br}^{\bullet}\right]$ and $R_{F}^{B r}$ that are good to within a factor of two. 
3.8 Application of probe technique to environmental samples

This technique was developed primarily to investigate halide oxidation by ${ }^{\bullet} \mathrm{OH}$, a process that is important in seawater (Zafiriou et al., 1987; Zhou and Mopper, 1990), sea-salt particles (Matthew et al., 2003), and possibly in snow (Chu and Anastasio, 2005). Because the kinetic model was written based on the ${ }^{\bullet} \mathrm{OH}$-initiated oxidation of bromide, and because this model is an integral part of the technique, ${ }^{\bullet} \mathrm{OH}$ kinetics in the sample must be measured (e.g., with the benzoate technique; Zhou and Mopper, 1990) so that $R_{F}^{\mathrm{OH}}$, $\left[{ }^{\bullet} \mathrm{OH}\right]$, and $\tau_{\mathrm{OH}}$ can be accurately represented in the model. The reactive halogen probe technique described here could be extended to examine halide oxidation by other mechanisms (e.g. ${ }^{\bullet} \mathrm{NO}_{3}$ or $\mathrm{O}_{3}$ ), but the kinetic equations and model would need to be modified in order to make the technique quantitative.

While the experiments described here were all performed on laboratory solutions, our analytical technique is sensitive enough that the method should also work on environmental samples. We have not yet applied the method to environmental samples, but we explore the issue of method sensitivity in the context of these types of samples in more detail in Part 2. Furthermore, this technique can be used to elucidate mechanisms of halide oxidation in laboratory solutions by comparing experimental results with model predictions. For example, we have used the technique in bromide solutions to determine that $\mathrm{HO}_{2}^{\bullet}$ oxidizes dibromide radical anion $\left({ }^{\bullet} \mathrm{Br}_{2}^{-}\right)$ to $\mathrm{Br}_{2}$ rather than reducing it to $\mathrm{Br}^{-}$as is generally assumed (Matthew et al., 2003). Finally, this allyl alcohol technique (or analogous techniques using different probe compounds) could also be used to examine the abiotic halogenation of organics in environmental samples under various conditions.

\subsection{Technique limitations}

While the chemical probe technique described here generally does a good to excellent job under the specified experimental conditions, it does have some limitations. The biggest limitation stems from the fact that the method is relatively nonspecific, i.e., the 3BPD product is formed by at least $\mathrm{Br}^{\bullet}, \mathrm{Br}_{2}$, and $\mathrm{HOBr}$. Accounting for the relative amounts of $3 \mathrm{BPD}$ formed from each $\mathrm{Br}^{*}(\mathrm{aq})$ species requires calculating values of $F_{i}^{3 \mathrm{BPD}}$ (Sect. S.4), which requires obtaining values of $[i]$ from a model that represents the experimental system. Thus in environmental samples (e.g., seawater or sea-salt particles) where the halide chemistry might not be completely known, model values of $F_{i}^{3 \mathrm{BPD}}$ could be incorrect, which would bias experimental values of $[i], R_{F}^{i}$, and $\tau_{i}$. However, this bias is likely to be small since the reactions controlling the relative amounts of $\mathrm{Br}^{*}(\mathrm{aq})$ are very rapid and well characterized as a function of halide concentration and $\mathrm{pH}$ (e.g., Table S2). In addition, in cases where one $\mathrm{Br}^{*}(\mathrm{aq})$ species is responsi- ble for the majority of 3BPD, we expect that model values of $F_{i}^{3 \mathrm{BPD}}$ will have little bias.

A second limitation with this technique is the selection of a data treatment $(\mathrm{A}, \mathrm{B}$, or $\mathrm{C})$ for sample analysis. In this study, where the conditions were tightly controlled, it was possible to calculate model-derived expected values for the experimental systems and use these values to determine what data treatment would give the most accurate results. For actual samples this selection process is not possible and we must rely on the observations from this study to select the best data treatment. In doing this, we make the assumption that the relative merits of the data treatments found in this study are applicable to environmental samples. While this should be true in samples with conditions similar to the laboratory solutions studied here, this assumption needs to be experimentally tested.

\section{Conclusions}

We have developed a chemical probe technique for the detection and quantification of reactive bromide species $\left(\mathrm{Br}^{*}(\mathrm{aq})=\mathrm{Br}^{\bullet}, \mathrm{Br}_{2}, \mathrm{HOBr}\right.$, etc. $)$ based on the reaction of $\mathrm{Br}$ (aq) with allyl alcohol (AA) to form 3-bromo,1,2propanediol (3BPD). The model used to validate the probe technique was constrained by several different sets of experimental data where $\mathrm{pH},\left[\mathrm{Br}^{-}\right]$, and $[\mathrm{AA}]$ were varied. With this technique, the steady state concentrations $([i])$, rates of formation $\left(R_{F}^{i}\right)$ and lifetimes $\left(\tau_{i}\right)$ of $\mathrm{Br}^{*}(\mathrm{aq})$ can be measured in aqueous bromide solutions.

Three data treatments (A, B, and C) capable of calculating [i], $R_{F}^{i}$, and $\tau_{i}$, were evaluated with model experiments and then applied to the experimental data. Data treatment $C$ was shown to consistently produce the best results for $[i], R_{F}^{i}$, and $\tau_{i}$ for the $\mathrm{Br}^{*}(\mathrm{aq})$ species considered here. With treatment C, experimental values of $[i]$ and $R_{F}^{i}$ for all species are typically within a factor of 2.5 of the expected values (values of [i] are often much better than this), while $\tau_{i}$ values for all species are generally within a factor of 3 of expected values. All three data treatments rely on the use of kinetic models to determine the fraction of 3BPD formed from $\mathrm{Br}^{\circ}, \mathrm{Br}_{2}$, and $\mathrm{HOBr}$ (i.e., $F_{i}^{3 \mathrm{BPD}}$ ) for a given set of conditions. This is a disadvantage of the technique because of the possibility of error in the model.

This technique provides researchers with a new tool that allows further investigation of aqueous halide chemistry, halide oxidation mechanisms and reactive halogen dynamics in aqueous solution. It can also be used to examine the formation of halogenated organics and release of photoactive gas-phase species in environmental samples (such as sunlit surface seawater and sea-salt particles) under environmentally relevant conditions.

Acknowledgements. This work was supported by a NASA Earth System Science Fellowship (to B. M. Matthew), by the National Science Foundation (ATM-9701995), and by a University of 
California, Davis (UCD) Jastro Shields Fellowship. The authors thank A. Jordan, J. Chang, J. Smith, J. Olivarez, and I. George for their assistance.

Edited by: M. Ammann

\section{References}

Anastasio, C., Faust, B. C., and Allen, J. M.: Aqueous phase photochemical formation of hydrogen peroxide in authentic cloud waters, J. Geophys. Res., 99, 8231-8248, 1994.

Anastasio, C. and Matthew, B. M.: A chemical probe technique for the determination of reactive halogen species in aqueous solution: Part 2 - Chloride solutions and mixed bromide/chloride solutions, Atmos. Chem. Phys., 6, 2439-2451, 2006, http://www.atmos-chem-phys.net/6/2439/2006/.

Anastasio, C. and McGregor, K. G.: Chemistry of fog waters in California's Central Valley: 1. In situ photoformation of hydroxyl radical and singlet molecular oxygen, Atmos. Environ., 35, 1079-1089, 2001.

Arakaki, T., Anastasio, C., Shu, P. G., and Faust, B. C.: Aqueousphase photoproduction of hydrogen peroxide in authentic cloud waters - wavelength dependence, and the effects of filtration and freeze-thaw cycles, Atmos. Environ., 29, 1697-1703, 1995.

Arakaki, T. and Faust, B. C.: Sources, sinks, and mechanisms of hydroxyl radical $(\cdot \mathrm{OH})$ photoproduction and consumption in authentic acidic continental cloud waters from Whiteface Mountain, New York: The role of the Fe(r) (r=II,III) photochemical cycle, J. Geophys. Res., 103, 3487-3504, 1998.

Barrie, L. A., Bottenheim, J., Schnell, R. C., Crutzen, P. J., and Rasmussen, R. A.: Ozone destruction and photochemical reactions at polar sunrise in the lower Arctic atmosphere, Nature, 334, 138-141, 1988.

Bottenheim, J., Fuentes, J. D., Tarasick, D. W., and Anlauf, K. G.: Ozone in the Arctic lower troposphere during winter and spring 2000 (ALERT2000), Atmos. Environ., 36, 2535-2544, 2002.

Braun, W., Herron, J. T., and Kahaner, D. K.: Acuchem: A computer program for modeling complex chemical reaction systems, Int. J. Chem. Kin., 20, 51-62, 1988.

Chu, L. and Anastasio, C.: Formation of hydroxyl radical from the photolysis of frozen hydrogen peroxide, J. Phys. Chem. A, 109, 6264-6271, 2005.

Ebinghaus, R., Kock, H. H., Temme, C., Einax, J. W., Lowe, A. G., Richter, A., Burrows, J. P., and Schroeder, W. H.: Antarctic springtime depletion of atmospheric mercury, Environ. Sci. Technol., 36, 1238-1244, 2002.

Faust, B. C. and Allen, J. M.: Aqueous-phase photochemical formation of hydroxyl radical in authentic cloudwaters and fogwaters, Environ. Sci. Technol., 27, 1221-1224, 1993.

Foster, K. L., Plastridge, R. A., Bottenheim, J. W., Shepson, P. B., Finlayson-Pitts, B. J., and Spicer, C. W.: The role of $\mathrm{Br}_{2}$ and $\mathrm{BrCl}$ in surface ozone destruction at polar sunrise, Science, 291, 471-474, 2001.

Galbally, I. E., Bentley, S. T., and Meyer, C. P.: Mid-latitude marine boundary-layer ozone destruction at visible sunrise observed at Cape Grim, Tasmania, 41 degrees south, Geophys. Res. Lett., 27, 3841-3844, 2000.
Gratzel, M. and Halmann, M.: Photosensitized oxidation of bromide in Dead Sea water, Mar. Chem., 29, 169-182, 1990.

Hebestreit, K., Stutz, J., Rosen, D., Matveiv, V., Peleg, M., Luria, M., and Platt, U.: DOAS measurements of tropospheric bromine oxide in mid-latitudes, Science, 283, 55-57, 1999.

Jobson, B. T., Niki, H., Yokouchi, Y., Bottenheim, J., Hopper, F., and Leaitch, R.: Measurements of $\mathrm{C}_{2}-\mathrm{C}_{6}$ hydrocarbons during the Polar Sunrise 1992 Experiment: Evidence for $\mathrm{Cl}$ atom and Br atom chemistry, J. Geophys. Res., 99, 25 355-25 368, 1994.

Keene, W. C. and Savoie, D. L.: Correction to "The pH of deliquesced sea-salt aerosol in polluted marine air" (vol. 26, p. 1315, 1999), Geophys. Res. Lett., 26, 1315-1316, 1999.

Lindberg, S. E., Brooks, S., Lin, C. J., Scott, K. J., Landis, M. S., Stevens, R. K., Goodsite, M., and Richter, A.: Dynamic oxidation of gaseous mercury in the Arctic troposphere at polar sunrise, Environ. Sci. Technol., 36, 1245-1256, 2002.

March, J.: Advanced Organic Chemistry: Reactions, Mechanisms, and Structure, Wiley, New York, 1992.

Matthew, B. M. and Anastasio, C.: Determination of halogenated mono-alcohols and diols in water by gas chromatography with electron-capture detection, J. Chromatogr. A, 866, 65-77, 2000.

Matthew, B. M., George, I., and Anastasio, C.: Hydroperoxyl radical $\left(\mathrm{HO}_{2}\right)$ oxidizes dibromide radical anion $\left.\left(\mathrm{Br}_{2}\right)^{-}\right)$to bromine $\left(\mathrm{Br}_{2}\right)$ in aqueous solutions: Implications for the formation of $\mathrm{Br}_{2}$ in the marine boundary layer, Geophys. Res. Lett., 30, 22972301, 2003.

McConnell, J. C., Henderson, G. S., Barrie, L., Bottenheim, J., Niki, H., Langford, C. H., and Templeton, E. M. J.: Photochemical bromine production implicated in Arctic boundary-layer ozone depletion, Nature, 355, 150-152, 1992.

Michalowski, B., Francisco, J. S., Li, S., Barrie, L. A., Bottenheim, J. W., and Shepson, P. B.: A computer model study of multiphase chemistry in the Arctic boundary layer during polar sunrise, J. Geophys. Res., 105, 15 131-15 145, 2000.

Miller, W. L. and Kester, D. R.: Hydrogen peroxide measurement in seawater by p-hydroxyphenylacetic acid dimerization, Anal. Chem., 60, 2711-2715, 1988.

Moore, R. M. and Zafiriou, O. C.: Photochemical production of methyl-iodide in seawater, J. Geophys. Res.-Atmos., 99, 1641516420, 1994.

Nagao, I., Matsumoto, K., and Tanaka, H.: Sunrise ozone destruction found in the sub-tropical marine boundary layer, Geophys. Res. Lett., 26, 3377-3380, 1999.

Richter, A., Wittrock, F., Eisinger, M., and Burrows, J. P.: GOME observations of tropospheric $\mathrm{BrO}$ in northern hemispheric spring and summer 1997, Geophys. Res. Lett., 25, 2683-2686, 1998.

Sander, R. and Crutzen, P. J.: Model study indicating halogen activation and ozone destruction in polluted air masses transported to the sea, J. Geophys. Res., 101, 9121-9138, 1996.

Stutz, J., Ackermann, R., Fast, J. D., and Barrie, L. A.: Atmospheric reactive chlorine and bromine at the Great Salt Lake, Utah, Geophys. Res. Lett., 29, 181-184, 2002.

Swanson, A. L., Blake, N. J., Dibb, J. E., Albert, M. R., Blake, D. R., and Rowland, F. S.: Photochemically induced production of $\mathrm{CH}_{3} \mathrm{Br}, \mathrm{CH}_{3} \mathrm{I}, \mathrm{C}_{2} \mathrm{H}_{5} \mathrm{I}$, ethene, and propene within surface snow at Summit, Greenland, Atmos. Environ., 36, 2671-2682, 2002.

Vogt, R., Sander, R., and Crutzen, P. J.: A mechanism for halogen release form sea-salt aerosol in the remote marine boundary layer, Nature, 383, 327-330, 1996. 
von Glasow, R., Sander, R., Bott, A., and Crutzen, P.: Modeling halogen chemistry in the marine boundary layer. 1. Cloud-free MBL, J. Geophys. Res., 107, 4341, doi:10.109/2001JD000942, 2002a.

von Glasow, R., Sander, R., Bott, A., and Crutzen, P.: Modeling halogen chemistry in the marine boundary layer: 2. Interactions with sulfur and cloud-covered MBL, J. Geophys. Res., 107, 4323, doi:10.1029/2001JD000943, 2002b.

Zafiriou, O. C., True, M. B., and Hayon, E.: Consequences of $\mathrm{OH}$ radical reaction in sea water: Formation and decay of $\mathrm{Br}_{2}^{-}$ion radical, in: Photochemistry of Environmental Aquatic Systems, edited by: Zika, R. G. and Cooper, W. J., American Chemical Society, Washington D.C., 89-105, 1987.
Zepp, R. G., Faust, B. C., and Hoigné, J.: Hydroxyl radical formation in aqueous reactions ( $\mathrm{pH} 3-8)$ of Iron(II) with hydrogen peroxide: The photo-Fenton reaction, Environ. Sci. Technol., 26, 313-319, 1992.

Zhou, X. and Mopper, K.: Determination of photochemically produced hydroxyl radicals in seawater and freshwater, Mar. Chem., 30, 71-88, 1990. 